\title{
Effects of Synthetic Anti-Inflammatory Sterol in CB3V-Induced Myocarditis: A Morphological Study on Heart Muscle Tissue
}

\author{
Paola Castrogiovanni ${ }^{1}$, Francesca Maria Trovato ${ }^{2, *}$, Marta Anna Szychlinska ${ }^{1}$, Carla Loreto ${ }^{1}$, \\ Salvatore Giunta ${ }^{1}$, Soraya Scuderi 1,3, Roberta Passanisi 1,4, Federica Fidone ${ }^{2}$, Paolo Fagone ${ }^{5}$, \\ Rosa Imbesi ${ }^{1}$, Ferdinando Nicoletti ${ }^{5}$ and Sergio Castorina ${ }^{1,2}$
}

1 Department of Biomedical and Biotechnological Sciences, Human Anatomy and Histology Section, School of Medicine, University of Catania, 95123 Catania, Italy; pacastro@unict.it (P.C.); marta.sz@hotmail.it (M.A.S.); carla.loreto@unict.it (C.L.); salvatore.giunta15@virgilio.it (S.G.); sorayascuderi@yahoo.it (S.S.); robpassanisi@gmail.com (R.P.); roimbesi@unict.it (R.I.); sergio.castorina@unict.it (S.C.)

2 Department of Clinical and Experimental Medicine, Internal Medicine Division, School of Medicine, University of Catania, 95123 Catania, Italy; federicafidone@gmail.com

3 Yale Child Study Center, Yale School of Medicine, New Haven, CT 06510, USA

4 Hearth Center, “G.B. Morgagni” Mediterranean Foundation, Cardiology Unit, 95123 Catania, Italy

5 Department of Biomedical and Biotechnological Sciences, General Pathology Section, School of Medicine, University of Catania, 95123 Catania, Italy; paolofagone@yahoo.it (P.F.); ferdinic@unict.it (F.N.)

* Correspondence: trovatofrancesca@gmail.com; Tel.: +39-953-781-550; Fax: +39-953-781-549

Academic Editor: Giuseppe Musumeci

Received: 25 November 2015; Accepted: 2 February 2016; Published: 18 February 2016

\begin{abstract}
Cell-mediated immune events play a role in the pathogenesis of myocarditis provoked by Group B coxsackievirus (CVB). Studies indicated the synthetic derivative of androstene- $3 \beta, 7 \beta, 17 \beta-$ triol, HE3286 (17 $\alpha$-ethynyl-5-androstene-3 $3,7 \beta, 17 \beta$-triol), may ameliorate the course of immunoinflammatory and autoimmune diseases in rodents. The aim of this study was to evaluate effects of HE3286 on histological signs of CVB-induced myocarditis. BALB/c mice were infected with coxsackie B3 virus (CB3V) and treated by intraperitoneal administration of dexamethasone (Dex) or by oral gavage with HE3286 or with its vehicle, HERF405, for 18 days. Mice were sacrificed and hearts were explanted for histological and immunohistochemical analysis (TNF- $\alpha$, IL-6, MMP9, ADAM10 and HSP-70). Heart tissues of Dex-treated mice showed a better histological structure compared with mice treated with HERF405. An almost complete resolution of myocarditis was observed in HE3286-treated mice as evidenced by lack of inflammatory infiltration. Immunohistochemical findings confirmed HE3286 had a more pronounced effect than Dex in reducing inflammatory response associated with in situ modulation of cytokine expression and tissue remodeling. Our data demonstrate HE3286 has better results in inhibiting establishment and progression of murine CVB-induced myocarditis than Dex, suggesting this drug may also have a therapeutic role in treatment of CVB-induced myocarditis.
\end{abstract}

Keywords: myocarditis; heart muscle tissue; coxsackie virus; HE3286; histology; immunohistochemistry

\section{Introduction}

Myocarditis, characterized by inflammation of the myocardium associated with cardiac dysfunction [1,2], is divided into three categories: noninfectious, infectious and that in which the immune mechanism is triggered or maintained by an infection. The clinical signs are variable, from asymptomatic forms to severe pathological conditions. The heterogeneity of symptoms makes early diagnosis difficult and leads to underestimation of the real incidence of myocarditis. Since the majority 
of viral myocarditis is asymptomatic or oligosymptomatic, the use of diagnostic biopsy is infrequent and thus the possible viral cause is often not recognized. Viral myocarditis exhibits an inflammatory response which, if persistent or excessive, may lead to chronicization [2].

In spite of the experimental evidence suggesting that acute and chronic myocardial injury in myocarditis is due to an immune response involving $\mathrm{T}$ lymphocytes and autoreactive antibodies, the use of immunosuppressive therapies remains controversial as evidenced in several trials using treatments with prednisone and either azathioprine or cyclosporine [3].

Glucocorticoids are often administered in addition to hemodynamic support in myocarditis, to limit the acute inflammatory response [4-6]. However, the use of systemic immunosuppression in viral infection, with consequent induction of systemic immunosuppression, remains controversial for the treatment of viral myocarditis and studies aimed at identifying novel immunomodulatory drugs capable of tuning aberrant immune responses without inducing unwanted systemic immunosuppression.

Previous in vitro and in vivo studies by ourselves and others on HE3286 (17 $\alpha$-ethynyl-5-androstene$3 \beta, 7 \beta, 17 \beta$-triol), a synthetic derivative of androstene- $3 \beta, 7 \beta, 17 \beta$-triol, $17 \alpha$-ethynyl-5-androstene- $3 \beta, 7 \beta$, $17 \beta$-triol, showed that HE3286 ameliorates the course of immunoinflammatory and autoimmune diseases in rodent models without inducing systemic immunosuppression [7-14].

Recent evidence highlighted the immunopathogenetic mechanisms responsible for the development of CVB-induced myocarditis and focused on mediators that may play a role in the pathogenesis of the disease including the proinflammatory cytokines tumor necrosis factor- $\alpha$ (TNF- $\alpha$ ) and interleukin- 6 (IL-6) [15-18] and matrix metalloproteinases (MMPs) [19,20]. Furthermore, in the past, studies showed that in different cardiac-related pathologic conditions, such as ischemic heart disease, congestive heart failure, dilated cardiomyopathy, septic cardiomyopathy and myocarditis, cardiomyocytes were actively involved in cytokine biosynthesis [21,22].

The aim of our study was to evaluate the effects of HE3286 on the histological progression of CVB-induced myocarditis. We evaluated the impact of treatment with HE3286 or Dex in a mouse model of CVB-induced myocarditis and specifically on histological signs of disease and immunohistochemical detection of cytokines of TNF- $\alpha$, IL-6, MMP9, a disintegrin and metalloprotease-10 (ADAM10) and heat shock protein-70 (HSP-70) involved in molecular mechanisms of cardiomyopathies $[15,21,23]$ and other tissues [24-28]. Our results support that HE3286 has a stronger anti-inflammatory potential than Dex in reducing the inflammatory response in CB3V-induced myocarditis.

\section{Materials and Methods}

\subsection{Animals}

A total of $41 \mathrm{BALB} / \mathrm{c}$ male mice, 4-5 weeks old (Harlan Nossan, Correzzana, Italy), were housed in stainless steel cages during the entire stabling period. The animals were maintained under standard laboratory conditions $\left(20-22{ }^{\circ} \mathrm{C}\right.$; humidity of $40 \%-60 \%$; photoperiod of $12 / 12 \mathrm{~h}$, light and dark) with ad libitum food and water and were allowed to adapt one week to their environment before the experiment began. Ante- and post-mortem examinations were conducted by a veterinary surgeon to establish the state of health of each subject (according to Community Regulation CE n. 854/04 and council of 29 April 2004).

\subsection{Drugs}

Test compound $17 \alpha$-ethynyl-5-androstene-3 $\beta, 7 \beta, 17 \beta$-triol (HE3286), vehicle (HERF405) and dexamethasone (Dex) were provided by HollisEden Pharmaceuticals (San Diego, CA, USA). HERF405 contained $0.1 \%$ carboxymethylcellulose, $2 \%$ polysorbate 80 and $0.1 \%$ metabisulfite in phosphate-buffered saline $\mathrm{pH}$ 7.4. Healthy animals (controls) were treated with an equal volume of vehicle. 


\subsection{Experimental Design}

Mice were treated by oral gavage with HE3286 $80 \mathrm{mg} / \mathrm{kg}$ or vehicle HERF405, or intraperitoneally with dexamethasone (Dex) at the dose of $0.4 \mathrm{mg} / \mathrm{kg}$ for 18 consecutive days.

The 41 animals were divided into 4 groups:

(1) HE3286-treated mice $(n=12)$;

(2) Dex-treated mice $(n=12)$;

(3) HERF405-treated mice $(n=12)$;

(4) Control (healthy) mice $(n=5)$.

Treatment started on the day of intraperitoneal infection with coxsackie B3 virus (CB3V), and was continued up to the 18th day post-infection when the mice were sacrificed and hearts collected for histological analyses. This period of time for sacrifice of the mice was chosen according to literature data showing that the peak of inflammatory infiltrate post-CVB3 challenge occurs 2-3 weeks after challenge. We started the treatment the same day of intraperitoneal infection with coxsackie B3 virus in order to evaluate the possible role of HE3286, not only in the progression of murine CVB-induced myocarditis, but also in inhibiting establishment of the disease. The HERF405-treated mice group was considered as the control of the coxsackie B3 virus infection (pathogenic model group). Animals were monitored twice daily, 7 days a week, for health status recording body weight. The day of the sacrifice, hearts were weighed and submitted for histological analysis and immunohistochemistry.

\subsection{Histology and Histochemistry}

Heart tissue was collected from each animal and fixed in 10\% buffered formalin for $2 \mathrm{~h}$; after an overnight wash, specimens were dehydrated in graded ethanol, cleared in xylene and paraffin-embedded. Sections 3-4 $\mu \mathrm{m}$ in thickness were cut from paraffin blocks using a rotary microtome (Leica RM2235; Leica Microsystems, Wetzlar, Germany), mounted on silane-coated slides (Dako, Glostrup, Denmark), and air-dried. Slides were dewaxed in xylene, hydrated in graded ethanol, and stained with Hematoxylin and Eosin (H and E) for histopathological evaluations to highlight the presence or absence of structural alterations. The sections were examined with a Zeiss Axioplan light microscope (Carl Zeiss; Oberkochen, Germany) and photographed with a digital camera (AxioCam MRc5, Carl Zeiss).

\subsection{Immunohistochemistry (IHC)}

For immunohistochemical analysis, specimens were processed as previously described [29]. Briefly, the slides were dewaxed in xylene, hydrated using graded ethanol and were incubated for 30 min in $0.3 \% \mathrm{H}_{2} \mathrm{O}_{2} /$ methanol solution to quench endogenous peroxidase activity and then rinsed for 20 min with phosphate-buffered saline (PBS; Sigma, Milan, Italy). The sections were heated (5 $\mathrm{min} \times 3$ ) in capped polypropylene slide-holders with citrate buffer (10 mM citric acid, $0.05 \%$ Tween $20, \mathrm{pH} 6.0$; Bio-Optica, Milan, Italy), using a microwave oven $(750 \mathrm{~W})$ to unmask antigenic sites. The blocking step was performed before application of the primary antibody with $5 \%$ bovine serum albumin (BSA; Sigma, Milan, Italy) in PBS for $1 \mathrm{~h}$ in a humid chamber. BSA was used as a blocking agent to prevent non-specific binding of the antibody. Following blocking, the sections were incubated overnight at $4{ }^{\circ} \mathrm{C}$ with mouse monoclonal anti-TNF $\alpha$ antibody (sc-130349, Santa Cruz Biotechnology, Inc., Dallas, TX, USA) diluted 1:100 antibody diluent (Dako, Agilent Technologies Company, Santa Clara, CA, USA); goat polyclonal Anti-IL-6 antibody (sc-1265-R, Santa Cruz Biotechnology, Inc.) diluted 1:100 in antibody diluent (Dako, Agilent Technologies Company); mouse monoclonal Anti-MMP-9 antibody (NCL-MMP9-439, Novocastra Laboratories Ltd., Newcastle upon Tyne, UK) diluted 1:100 antibody diluent (Dako, Agilent Technologies Company); rabbit polyclonal Anti-ADAM10 antibody (ab 1997, Abcam plc, Cambridge, UK) diluted 1:100 antibody diluent (Dako, Agilent Technologies Company); mouse monoclonal Anti-HSP-70 antibody (sc-24, Santa Cruz Biotechnology, Inc.) diluted 1:100 in 
antibody diluent (Dako, Agilent Technologies Company). Immune complexes were then treated with a biotinylated link antibody (HRP-conjugated anti-mouse, anti-goat and anti-rabbit were used as secondary antibodies) and then detected with peroxidase labeled streptavin, both incubated for $10 \mathrm{~min}$ at room temperature (LSAB + System-HRP, K0690; Dako). The immunoreaction was visualized by incubating sections for $2 \mathrm{~min}$ in a $0.1 \%$ 3,3'-diaminobenzidine and $0.02 \%$ hydrogen peroxide solution (DAB substrate Chromogen System; Dako). The sections were lightly counterstained with Mayer's hematoxylin (Histolab Products AB, Göteborg, Sweden) mounted in GVA (Zymed Laboratories, San Francisco, CA, USA) and observed with an Axioplan Zeiss light microscope (Carl Zeiss, Oberkochen, Germany) and photographed with a digital camera (AxioCam MRc5, Carl Zeiss).

\subsection{Evaluation of Immunohistochemistry}

The antibodies-staining (TNF- $\alpha$, IL-6, MMP9, ADAM10 and HSP-70) status was identified as either negative or positive. Immunohistochemical positive staining was defined as the presence of brown chromogen detection on the edge of the hematoxylin-stained cell nucleus, distributed within the cytoplasm or in the membrane via evaluation by light microscopy as previously described [30]. Positive and negative controls were performed to test the specific reaction of primary antibodies used in this study at a protein level. Positive controls consisted of tissue specimens with known antigenic positivity. Sections treated with PBS without the primary antibodies served as negative controls. Seven fields, randomly selected from each section, were analyzed for morphometric and densitometric analysis. The percentage areas stained with antibodies (TNF- $\alpha$, IL-6, MMP9, ADAM10 and HSP-70), expressed as percentage positive, dark brown pixels of the analyzed fields, and the level (high/low) of staining intensity of positive areas, expressed as densitometric count (pixel2) of positive, dark brown pixels of the analyzed fields, were calculated using a software for image acquisition, (AxioVision Release 4.8.2-SP2 Software, Carl Zeiss Microscopy GmbH, Jena, Germany). Data were expressed as mean \pm standard deviation (SD). Statistical significance of results was thus accomplished. Digital micrographs were taken using the Zeiss Axioplan light microscope (Carl Zeiss) fitted with a digital camera (AxioCam MRc5, Carl Zeiss); evaluations were made by three blinded investigators, whose evaluations were assumed to be correct if values were not significantly different. In case of dispute concerning interpretation, the case was reconsidered to reach a unanimous agreement.

\subsection{Statistical Analysis}

Statistical analysis was performed using SPSS software (SPSS ${ }^{\circledR}$ release 16.0, Chicago, IL, USA). Data were tested for normality with the Kolmogorov-Smirnov test. All variables were normally distributed. Immunohistochemical comparisons between means were tested with one-way ANOVA post-test: Dunnett Multiple Comparisons Test. $p$-Values of less than 0.05 were considered statistically significant; $p$-values of less than 0.01 were considered statistically highly significant. Data are presented as the mean $\pm \mathrm{SD}$.

\section{Results}

\subsection{Histology and Histochemistry}

The histological analysis showed that heart muscle tissue from HE3286-treated mice had features similar to healthy control mice (Figure 1A,C). In contrast, in HERF405-treated mice, signs of damage in myocytes architecture persisted, showing loss of cellular organization, diffused/focal inflammatory infiltrate and micro hemorrhages (Figure 1B). In Dex-treated mice, though the heart tissue largely showed a better histological structure with respect to HERF405-treated mice, a number of inflammatory infiltration foci were evidenced (Figure 1D). The histological examination of the heart tissue showed a clear trend toward the resolution of myocarditis in mice treated with HE3286 compared to those treated with vehicle alone and also to those treated with Dex, suggesting a benefit particularly from treatment with HE3286. 

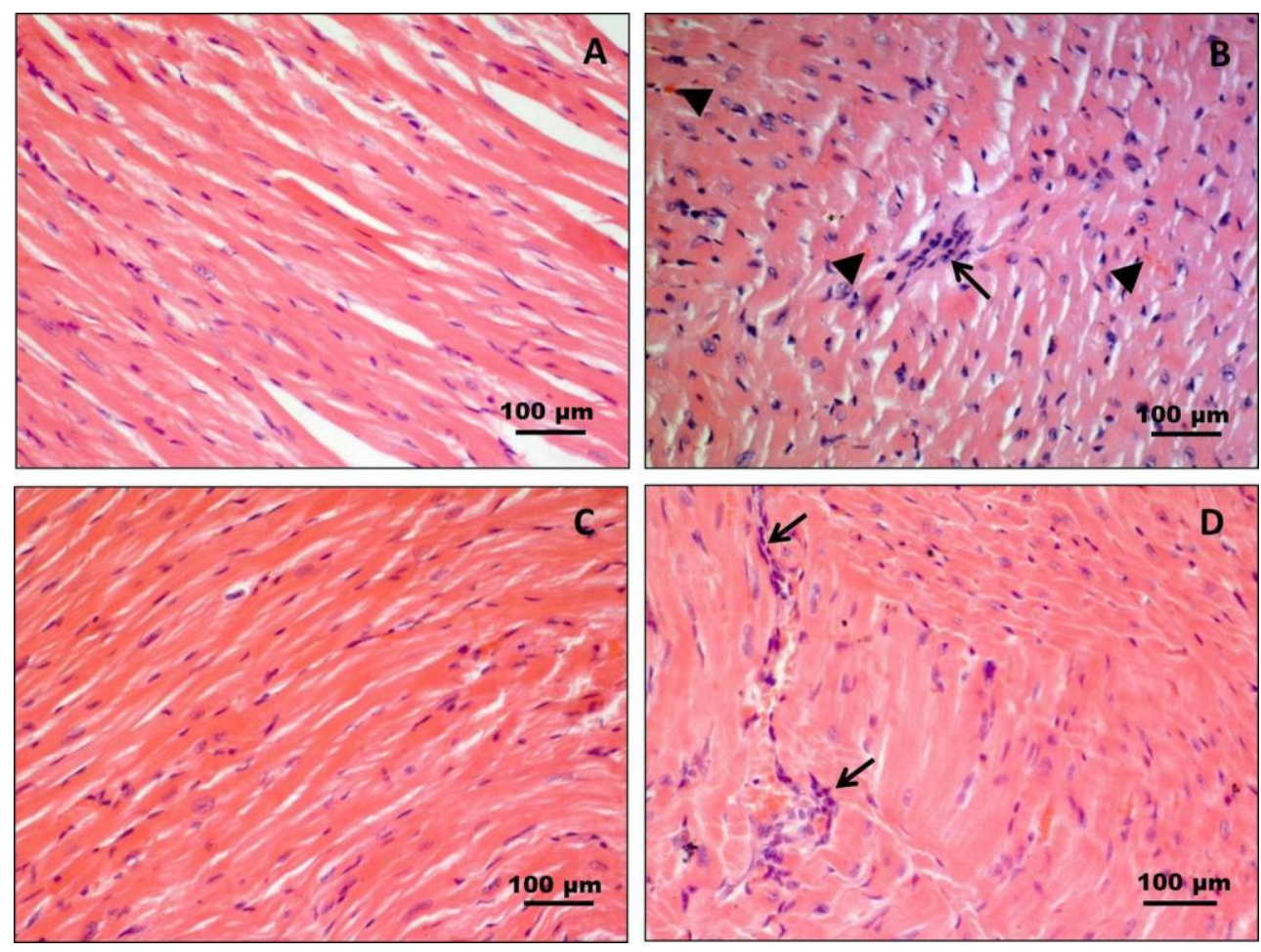

Figure 1. Histology of heart muscle tissue. Hematoxylin and Eosin staining. (A). Healthy control mice: heart tissue with normal morphology; (B) HERF405-treated mice: damaged myocytes architecture with loss of cellular organization, diffused/focal inflammatory infiltrate (black arrow) and microhemorrhages (black arrowheads); (C) HE3286-treated mice: heart tissue with features similar to healthy control mice; (D) Dex-treated mice: heart tissue with improved morphology but with a number of inflammatory infiltration foci (black arrows). Original magnification (A-D), 20×; scale bars: $(\mathbf{A}-\mathbf{D})=100 \mu \mathrm{m}$.

\subsection{Immunohistochemistry (IHC)}

We evaluated the expression of TNF- $\alpha$, IL-6, MMP9, ADAM10 and HSP-70, in mice heart tissue of all experimental groups. The percentage of stained areas (morphometric analysis) by TNF- $\alpha$, IL-6, MMP9, ADAM10 and HSP-70, and densitometric count (pixel ${ }^{2}$ ) (densitometric analysis), expressed by dark brown pixels of the analyzed fields, were considered.

\subsubsection{TNF- $\alpha$}

Morphometric analysis: Considering the percentage of stained areas in control healthy mice, no TNF- $\alpha$ immunostaining was detected (Figure 2A,E), in contrast to HERF405-treated mice (Figure 2B,E), in which it was very extensive $(14.85 \pm 1.14)(p<0.01)$, as a consequence of the inflammatory response in CB3V-induced myocarditis. In HE3286-treated mice (Figure 2C,E), TNF- $\alpha$ immunostaining was present only in traces $(0.91 \pm 0.14)$, comparable to that of control healthy mice $(p>0.05)$. In Dex-treated mice (Figure 2D,E), TNF- $\alpha$ immunolabeling was detected (6.28 \pm 0.79$)$ in a wider area with respect to HE3286-treated mice $(p<0.01)$, but in a smaller area compared to HERF405-treated mice $(p<0.01)$.

Densitometric analysis: Considering the densitometric count $\left(\mathrm{pixel}^{2}\right)$ as reported above, in control healthy mice, no TNF- $\alpha$ immunostaining was detected (Figure $2 \mathrm{~F}$ and insert in Figure 2A). In HERF405-treated mice, a mainly high TNF- $\alpha$ expression was evident with also a low TNF- $\alpha$ immunostaining (respectively red and green color in Figure 2F and insert in Figure 2B). In HE3286treated mice only traces of high mixed to low TNF- $\alpha$ immunostaining (respectively red and green color in Figure 2F and insert in Figure 2C) was detected. In Dex-treated mice, a mix of high and low TNF- $\alpha$ immunolabeling (respectively red and green color in Figure 2F and insert in Figure 2D) was 
highlighted, to a greater extent compared to HE3286-treated mice $(p<0.01)$, but to a lesser extent with respect to HERF405-treated mice $(p<0.01)$.
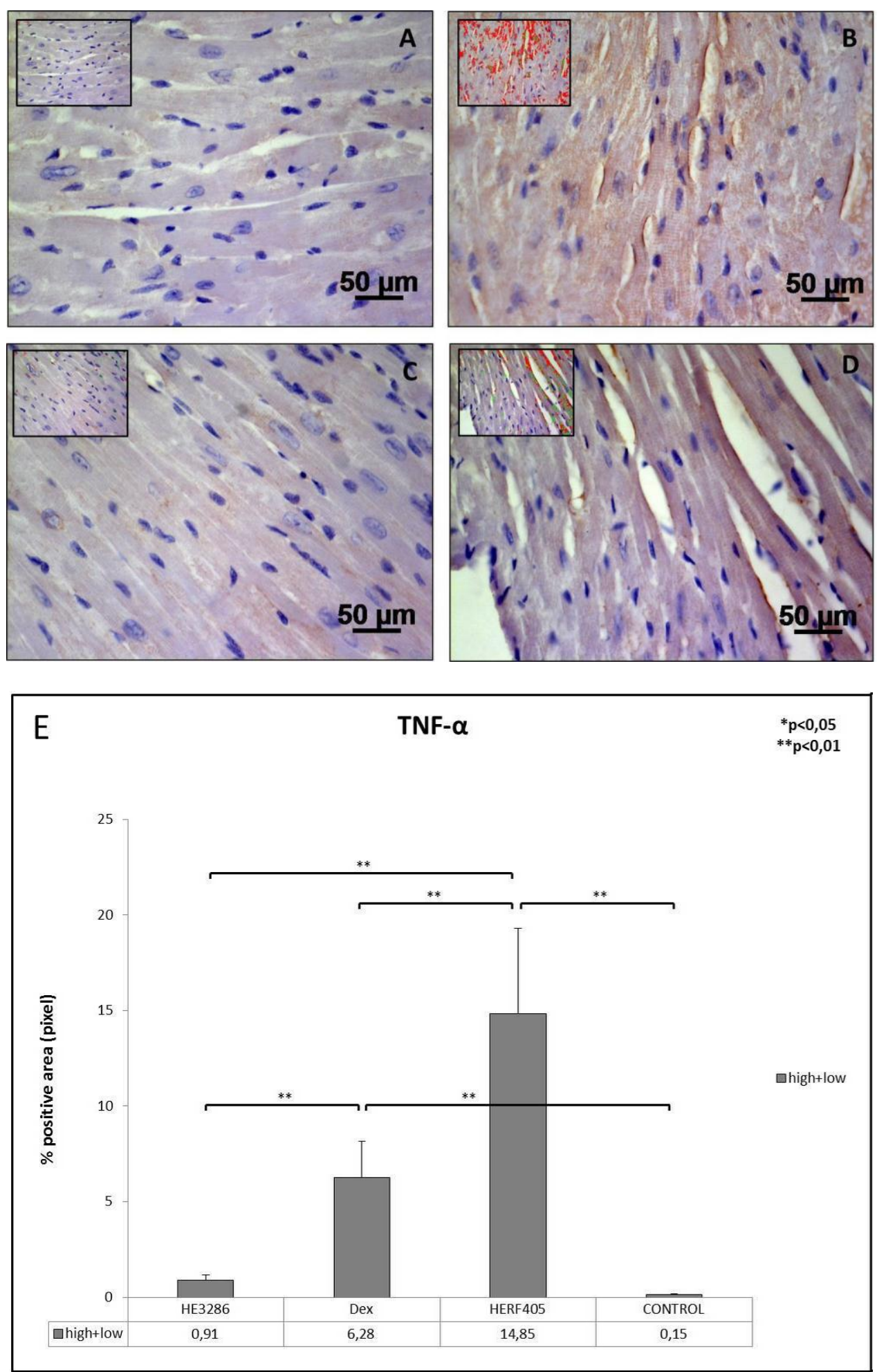

Figure 2. Cont. 


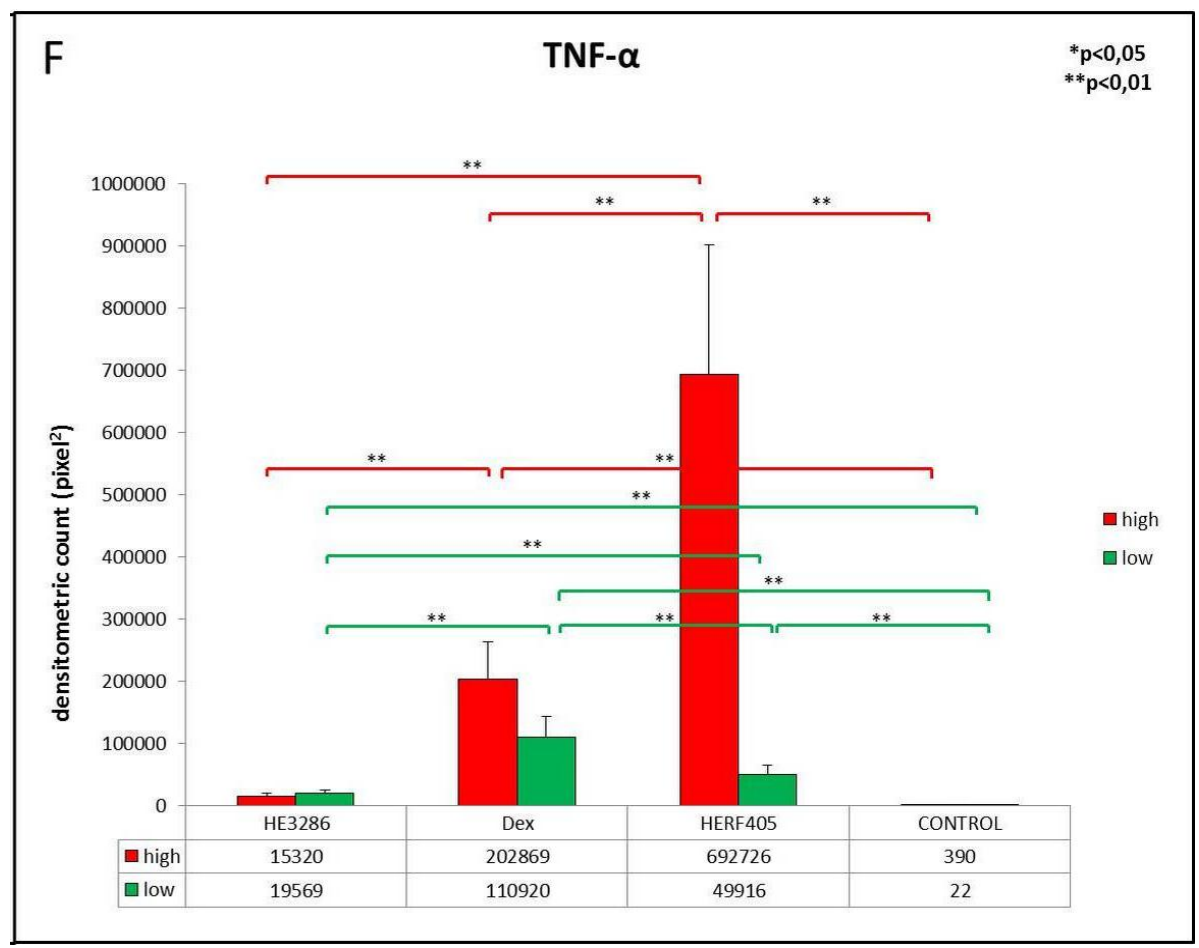

Figure 2. TNF- $\alpha$ immunostaining in mice CB3V-induced myocarditis. A-insert in (A) section of heart tissue of control healthy mice and its image analysis by software in which no TNF- $\alpha$ immunostaining was detected; B-insert in (B) section of heart tissue of experimental mice treated with vehicle alone (HERF405 group) in which TNF- $\alpha$ immunostaining was extensive; the relative image analysis by software in which a mainly high TNF- $\alpha$ expression was evident with also a low TNF- $\alpha$ immunostaining (respectively red and green color); C-insert in (C) section of heart tissue of experimental HE3286-treated mice in which TNF- $\alpha$ immunostaining was present only in traces, situation comparable to that of control healthy mice; the relative image analysis by software confirming the datum; D-insert in (D) section of heart tissue of experimental Dex-treated mice in which TNF- $\alpha$ immunolabeling was detected though in a smaller area compared to HERF405 group; the relative image analysis by software in which a mix of high and low TNF- $\alpha$ immunolabeling was highlighted (respectively red and green color); (A-D) original magnification 40× ; scale bar: $50 \mu \mathrm{m}$; (E) A bar chart representing a comparison of the percentage areas of TNF- $\alpha$-positive areas in HE3286 (n. 12), Dex (n. 12), HERF405 (n. 12)-treated mice vs. control healthy (n. 5) mice, expressed as percentage positive, dark brown pixels of the analyzed fields (total of high + low immunostaining); (F) A bar chart representing a comparison of the immunostaining intensity in TNF- $\alpha$-positive areas in HE3286 (n. 12), Dex (n. 12), HERF405 (n. 12)treated mice $v$ s. control healthy (n. 5) mice, expressed by densitometric count (pixel ${ }^{2}$ ) of dark brown pixels of the analyzed fields. Red bars, high immunostaining; green bars, low immunostaining. Data are presented as mean $\pm \mathrm{SD} .{ }^{*} p<0.05 ;{ }^{* *} p<0.01$.

\subsubsection{IL-6}

Morphometric analysis: As with TNF- $\alpha$, considering the percentage of stained areas in control healthy mice, no IL-6 immunostaining was detected (Figure 3A,E), whereas it was very extensive in HERF405-treated mice $(18.46 \pm 0.76)$ (Figure 3B,E) $(p<0.01)$, as a consequence of inflammatory response in CB3V-induced myocarditis. In HE3286-treated mice (Figure 3C,E), IL-6 immunostaining was detected as well as in Dex-treated mice (respectively, $8.5 \pm 1.02$ and $9.31 \pm 0.82$ ) (Figure 3D,E) $(p>0.05)$, but in a smaller area compared to HERF405-treated mice $(p<0.01)$.

Densitometric analysis: Considering the densitometric count ( $\mathrm{pixel}^{2}$ ) as reported above, in control healthy mice, no IL-6 immunostaining was detected (Figure 3F and insert in Figure 3A). In HERF405-treated mice, a high IL-6 expression was evident (red color in Figure 3F and insert in 
Figure 3B). In both HE3286-treated mice and Dex ones, a similar and mainly low IL-6 immunostaining was detected (green color in Figure 3F, inserts in Figure 3C,D) $(p>0.05)$, in contrast to the high IL-6 expression in HERF405-treated mice $(p<0.01)$.
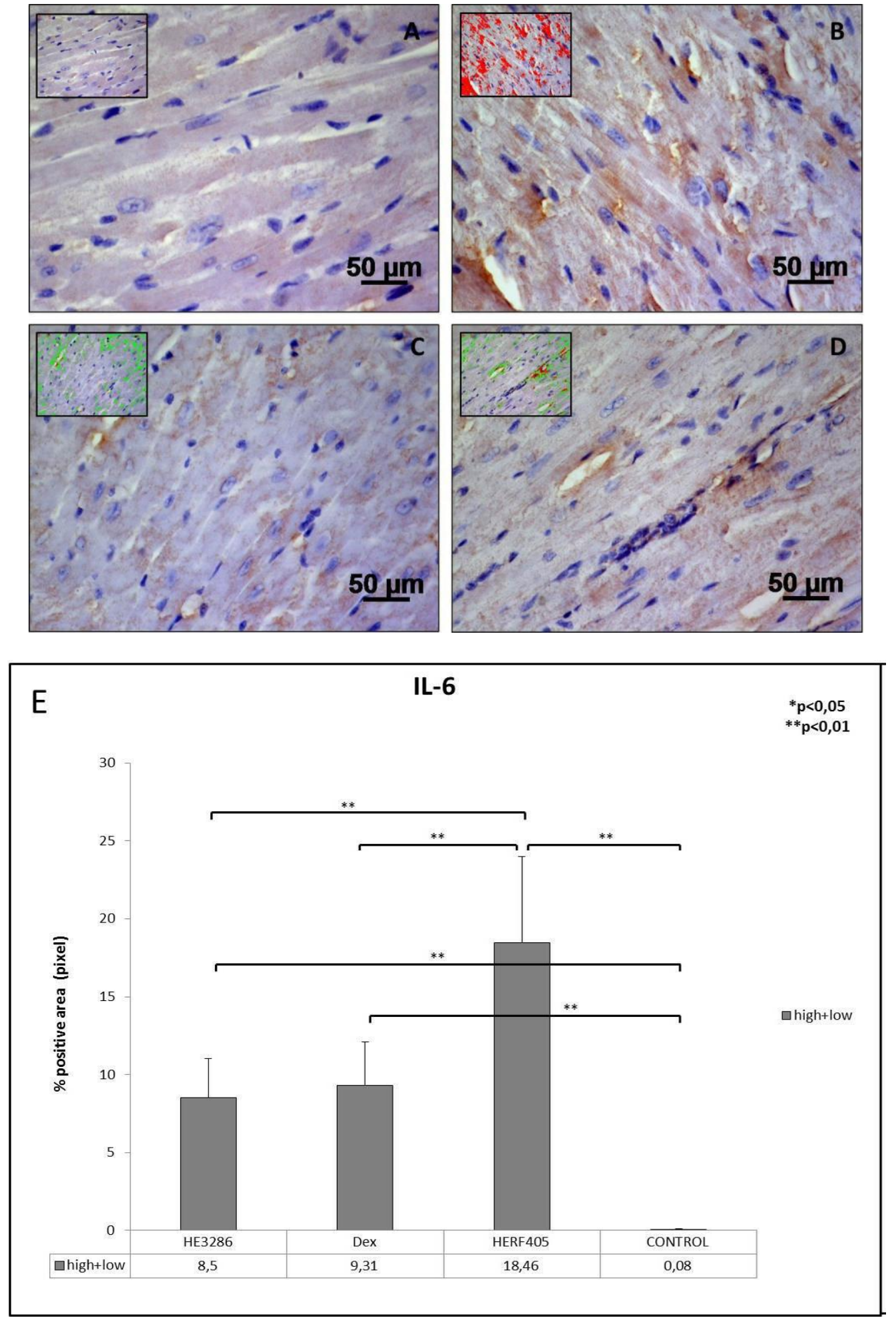

Figure 3. Cont. 


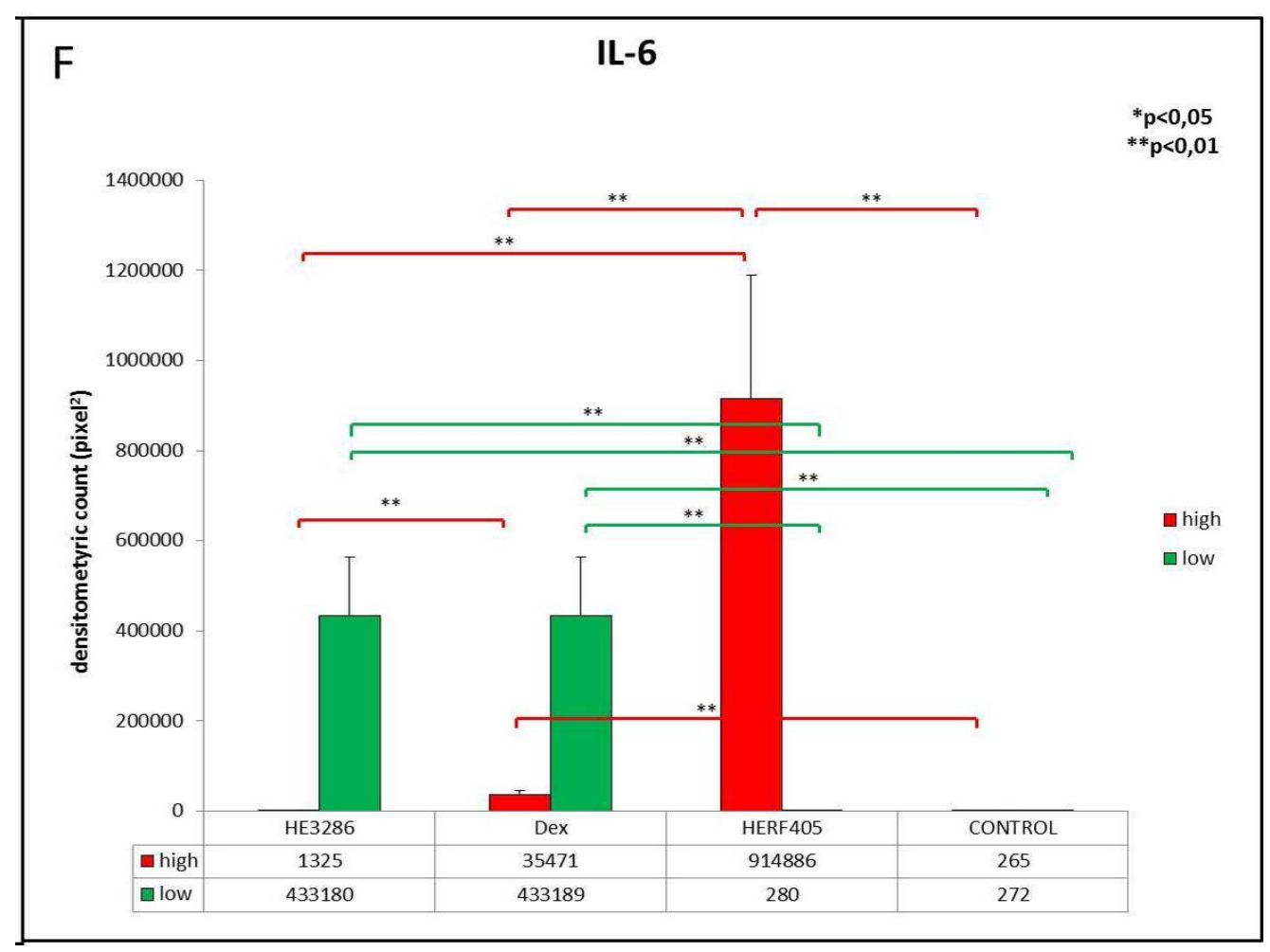

Figure 3. IL-6 immunostaining in mice CB3V-induced myocarditis. A-insert in (A) section of heart tissue of control healthy mice in which no IL-6 immunostaining was detected; the relative image analysis by software confirming the datum; B-insert in (B) section of heart tissue of experimental mice treated with vehicle alone (HERF405 group) in which IL-6 immunostaining was very extensive; the relative image analysis by software in which a high IL-6 expression was evident (red color); C-insert in (C) section of heart tissue of experimental HE3286-treated mice in which IL-6 immunostaining was detected; the relative image analysis by software in which a low IL-6 expression was detected and in a smaller area compared to HERF405 group (green color); D-insert in (D) section of heart tissue of experimental Dex-treated mice in which IL-6 immunostaining was detected as well as in HE3286 group; the relative image analysis by software in which a mainly low IL-6 expression was detected, similar to HE3286 group (green color); (A-D) original magnification 40×; scale bar: $50 \mu \mathrm{m}$; (E) A bar chart representing a comparison of the percentage areas of IL-6-positive areas in HE3286 (n. 12), Dex (n. 12), HERF405 (n. 12)-treated mice vs. control healthy (n. 5) mice, expressed as percentage positive, dark brown pixels of the analyzed fields (total of high + low immunostaining); (F) A bar chart representing a comparison of the immunostaining intensity in IL-6-positive areas in HE3286 (n. 12), Dex (n. 12), HERF405 ( $n$. 12)-treated mice vs. control healthy ( $n .5)$ mice, expressed by densitometric count $\left(\right.$ pixel $^{2}$ ) of dark brown pixels of the analyzed fields. Red bars, high immunostaining; green bars, low immunostaining. Data are presented as mean \pm SD. ${ }^{*} p<0.05 ;{ }^{* *} p<0.01$.

\subsubsection{MMP9}

Morphometric analysis: Considering the percentage of stained areas in control healthy mice, an almost undetectable MMP9 immunostaining was present $(0.136 \pm 0.05)$, in contrast to all other groups in which it was highly evident $(p<0.01)$ (Figure 4A,E). In HE3286-treated mice (Figure 4C,E), MMP9 immunostaining was extensive $(5.64 \pm 0.58)$ and similar to Dex-treated mice $(5.39 \pm 0.52)(p>0.05)$ (Figure 4D,E), but higher with respect to HERF405-treated mice $(5.01 \pm 0.47)(p<0.05)($ Figure 4B,E).

Densitometric analysis: Considering the densitometric count $\left(\mathrm{pixel}^{2}\right)$, in control mice, no MMP9 immunostaining was detected (Figure 4F and insert in Figure 4A). In HE3286-treated mice only a high MMP9 immunolabeling was evident (red color in Figure 4F and insert in Figure 4C) similar to 
Dextreated mice (red color in Figure 4F and insert in Figure 4D), though slightly lower $(p<0.05)$, but more evident than in HERF405-treated mice (red color in Figure 4F and insert in Figure 4B) $(p<0.01)$.
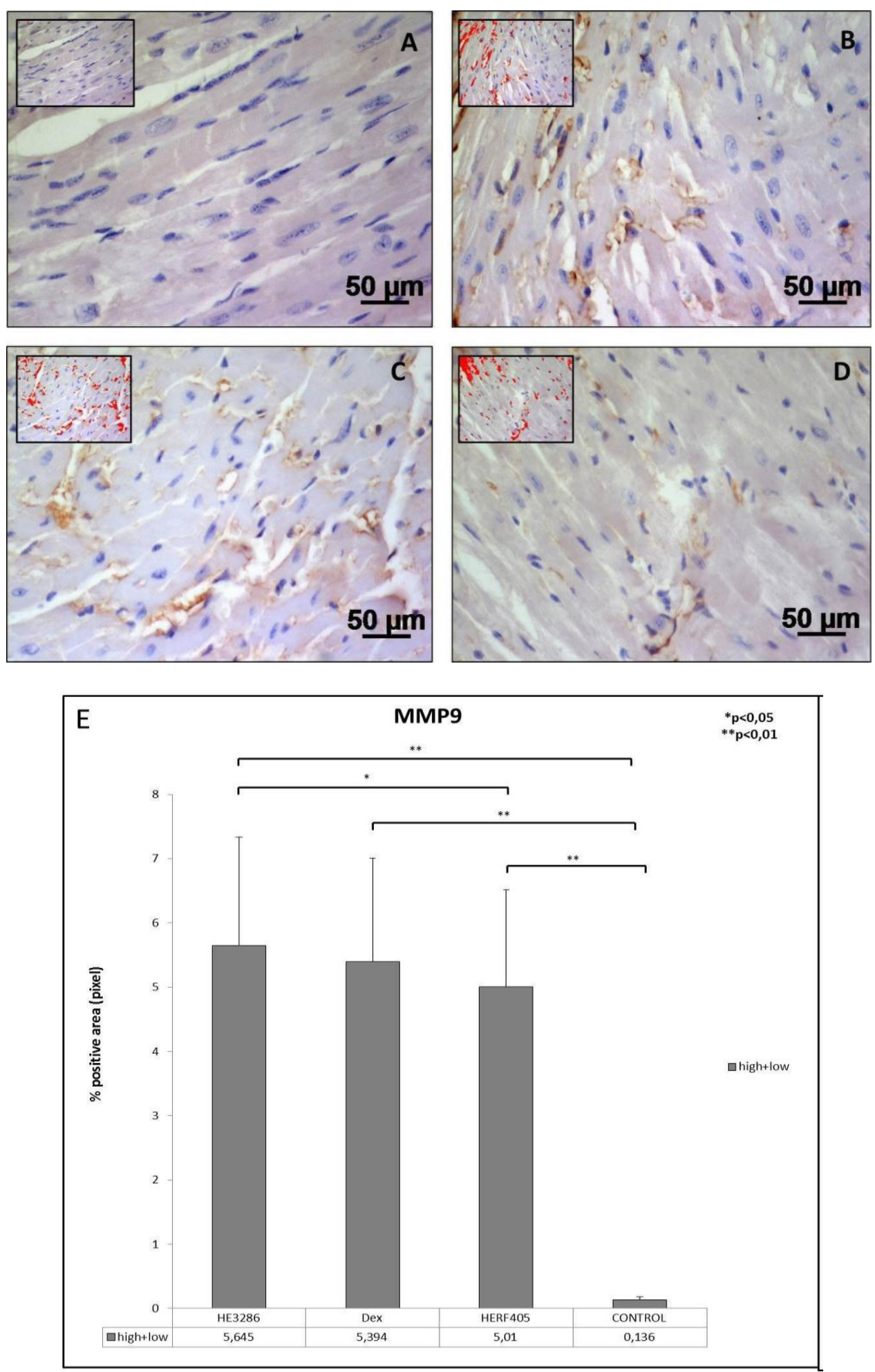

Figure 4. Cont. 


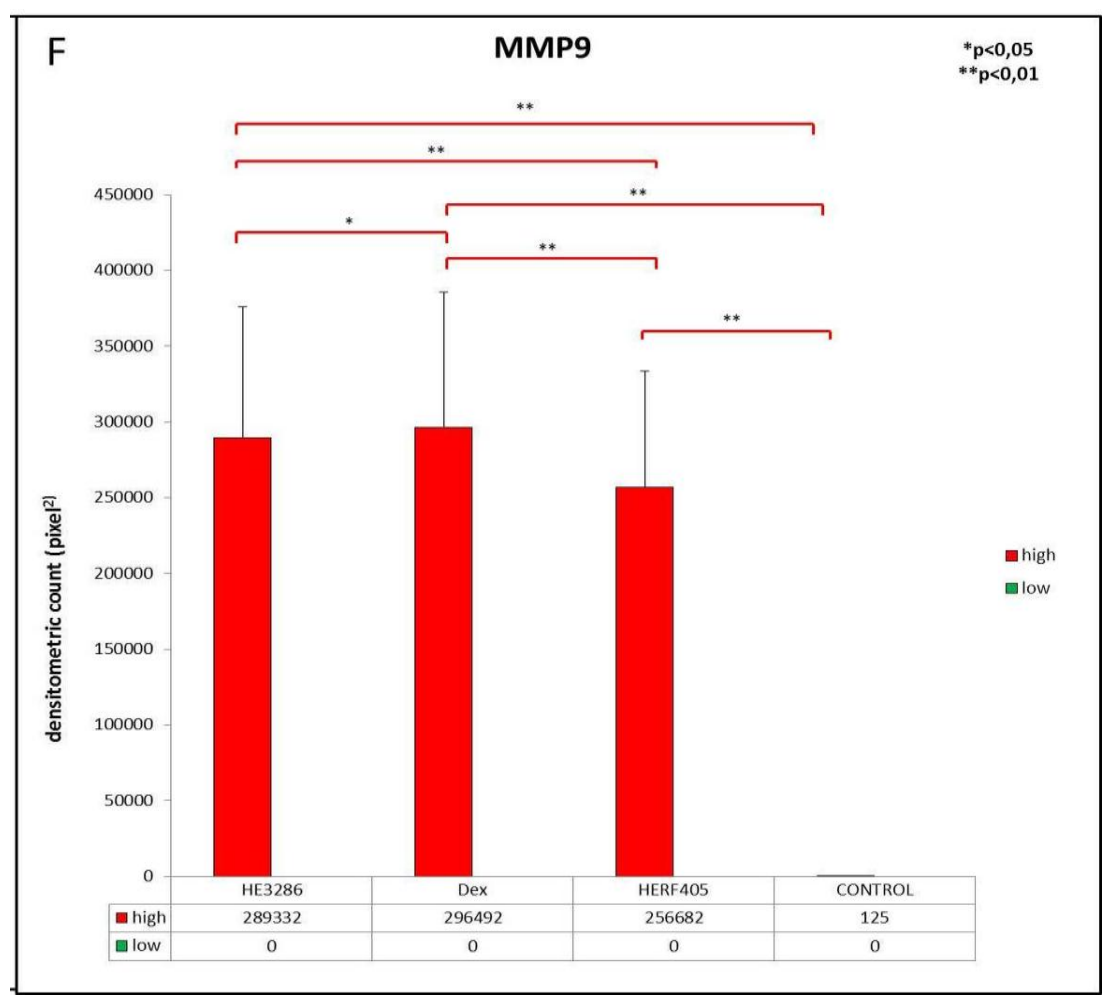

Figure 4. MMP9 immunostaining in mice CB3V-induced myocarditis. A-insert in (A) section of heart tissue of control healthy mice and the relative image analysis by software in which an almost undetectable MMP9 immunostaining was present; B-insert in (B) section of heart tissue of experimental mice treated with vehicle alone (HERF405 group) in which the MMP9 immunostaining was evident; the relative image analysis by software in which only a high MMP9 immunolabeling was highlighted (red color); C-insert in (C) section of heart tissue of experimental HE3286-treated mice in which MMP9 immunostaining was extensive; the relative image analysis by software in which only a high MMP9 immunolabeling was evident (red color); D-insert in (D) section of heart tissue of experimental Dex-treated mice in which MMP9 immunostaining was extensive and similar to HE3286 group; the relative image analysis by software in which only a high MMP9 immunolabeling was evident similarly to HE3286 group (red color); (A-D) original magnification $40 \times$; scale bar: $50 \mu \mathrm{m}$; (E) A bar chart representing a comparison of the percentage areas of MMP9-positive areas in HE3286 (n. 12), Dex (n. 12), HERF405 (n. 12)-treated mice vs. control healthy ( $n .5)$ mice, expressed as percentage positive, dark brown pixels of the analyzed fields (total of high + low immunostaining). (F) A bar chart representing a comparison of the immunostaining intensity in MMP9-positive areas in HE3286 (n. 12), Dex (n. 12), HERF405 ( $n$. 12)-treated mice vs. control healthy ( $n$. 5) mice, expressed by densitometric count $\left(\right.$ pixel $^{2}$ ) of dark brown pixels of the analyzed fields. Red bars, high immunostaining; green bars, low immunostaining. Data are presented as mean \pm SD. ${ }^{*} p<0.05 ; * * p<0.01$.

\subsubsection{ADAM10}

Morphometric analysis: Considering the percentage of stained areas in control healthy mice, ADAM10 immunostaining was detected to a low extent (3.11 \pm 0.27) (Figure 5A,E). In HE3286 and in Dex-treated mice, ADAM10 immunostaining was evident and similar (respectively $41.14 \pm 0.91$ and $40.26 \pm 1.28)(p>0.05)$, but to a lower extent compared to HERF405-treated mice $(53.11 \pm 1.61)$ $(p<0.01)$ (Figure 5B-E).

Densitometric analysis: Considering the densitometric count ( pixel $\left.^{2}\right)$, in control healthy mice, as reported above, ADAM10 immunostaining was detected to a low extent and it was mainly high (red color in Figure 5F and insert in Figure 5A). In HERF405-treated mice, a mainly low mixed to high ADAM10 immunolabeling was detected (respectively green and red color in Figure 5F and insert in 
Figure 5B) to a greater extent with respect to both HE3286 and Dex groups $(p<0.01)$. In HE3286-treated mice, a high ADAM10 immunostaining was detected with also a low ADAM10 immunostaining (respectively red and green color in Figure 5F and insert in Figure 5C). In Dex-treated mice, a mix of high and low ADAM10 immunolabeling (respectively red and green color in Figure 5F and insert in Figure 5D) was highlighted, to a slightly different extent compared to HE3286-treated mice $(p<0.01)$.
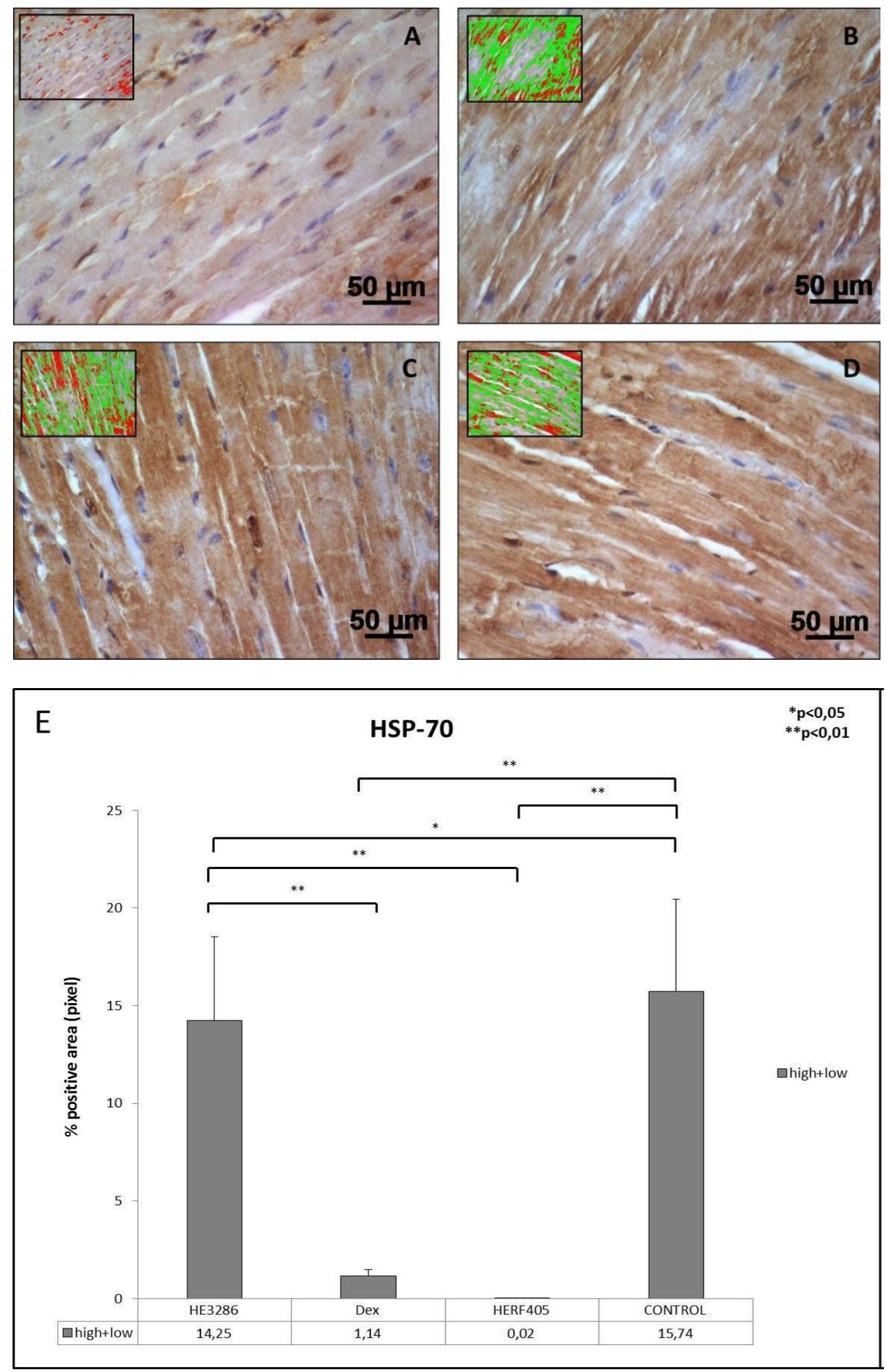

Figure 5. Cont. 


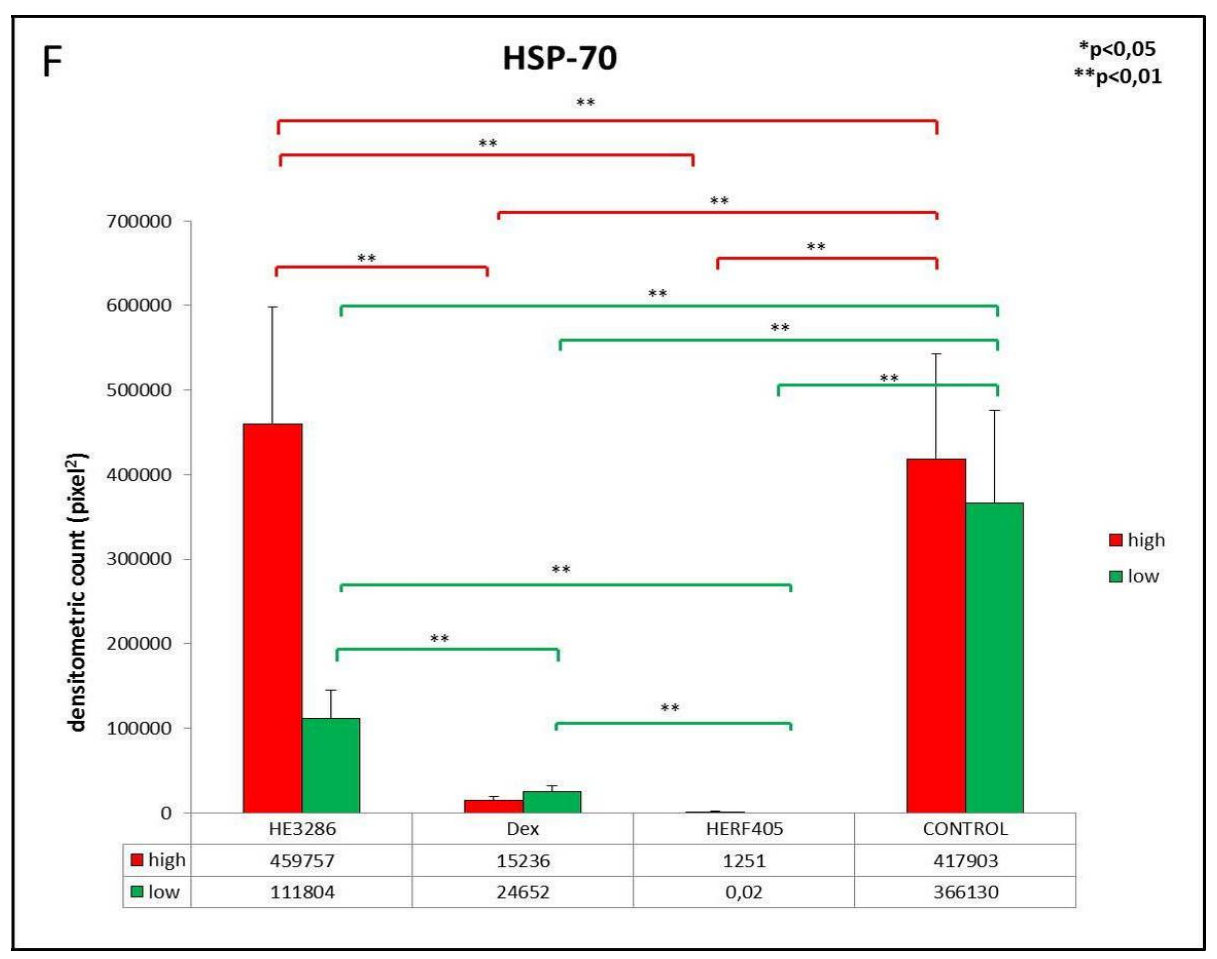

Figure 5. ADAM10 immunostaining in mice CB3V-induced myocarditis. A-insert in (A) section of heart tissue of control healthy mice in which ADAM10 immunostaining was detected to a low extent; the relative image analysis by software in which a mainly high ADAM10 immunostaining was shown (red color); B-insert in (B) section of heart tissue of experimental mice treated with vehicle alone (HERF405 group) in which the ADAM10 immunostaining was shown to a greater extent with respect to both HE3286 and Dex groups; the relative image analysis by software in which a mainly low mixed to high ADAM10 immunolabeling was detected (respectively green and red color); C-insert in (C) section of heart tissue of experimental HE3286-treated mice in which ADAM10 immunostaining was evident and similar to Dex group; the relative image analysis by software in which a high mixed to a low ADAM10 immunostaining was detected (respectively red and green color); D-insert in (D) section of heart tissue of experimental Dex-treated mice in which ADAM10 immunolabeling was evident and similar to HE3286 group; the relative image analysis by software in which a mix of high and low ADAM10 immunolabeling was detected (respectively red and green color); (A-D) original magnification $40 \times$; scale bar: $50 \mu \mathrm{m}$; (E) A bar chart representing a comparison of the percentage areas of ADAM10-positive areas in HE3286 ( $n .12)$, Dex (n. 12), HERF405 (n. 12)-treated mice vs. control healthy (n. 5) mice, expressed as percentage positive, dark brown pixels of the analyzed fields (total of high + low immunostaining); (F) A bar chart representing a comparison of the immunostaining intensity in ADAM10-positive areas in HE3286 (n. 12), Dex (n. 12), HERF405 (n. 12)-treated mice vs. control healthy ( $n$. 5) mice, expressed by densitometric count (pixel ${ }^{2}$ ) of dark brown pixels of the analyzed fields. Red bars, high immunostaining; green bars, low immunostaining. Data are presented as mean \pm SD. ${ }^{*} p<0.05 ; * * p<0.01$.

\subsubsection{HSP-70}

Morphometric analysis: Considering the percentage of stained areas, in control healthy mice, an extensive HSP-70 immunostaining was detected (15.74 \pm 1.78 ) (Figure 6A,E), in contrast to HERF405-treated mice (Figure 6B,E) in which it was absent $(0.02 \pm 0.01)(p<0.01)$ as a consequence of pathological events due to CB3V-induced myocarditis. In HE3286-treated mice (Figure 6C,E), HSP-70 immunostaining was evident and slightly lower than in control mice $(14.25 \pm 1.52)(p<0.05)$. In Dex-treated mice (Figure 6D,E), HSP-70 immunolabeling was slightly detected $(1.14 \pm 0.51)$ so that the difference with respect to HERF405-treated mice is not significant $(p>0.05)$. 
Densitometric analysis: Considering the densitometric count ( pixel $\left.^{2}\right)$ in control healthy mice, a high mixed to low HSP-70 immunostaining was detected (respectively red and green color in Figure $6 \mathrm{~F}$ and insert in Figure 6A). In HERF405-treated mice, as reported above, the HSP-70 immunolabeling was absent (Figure 6F and insert in Figure 6B). In HE3286-treated mice, a mainly high HSP-70 immunostaining was evident with also a low HSP-70 immunostaining (respectively red and green color in Figure 6F and insert in Figure 6C). In Dex-treated mice, a mix of high and low HSP-70 immunolabeling (respectively red and green color in Figure 6F and insert in Figure 6D) was highlighted, to a much smaller extent compared to HE3286-treated mice $(p<0.01)$.
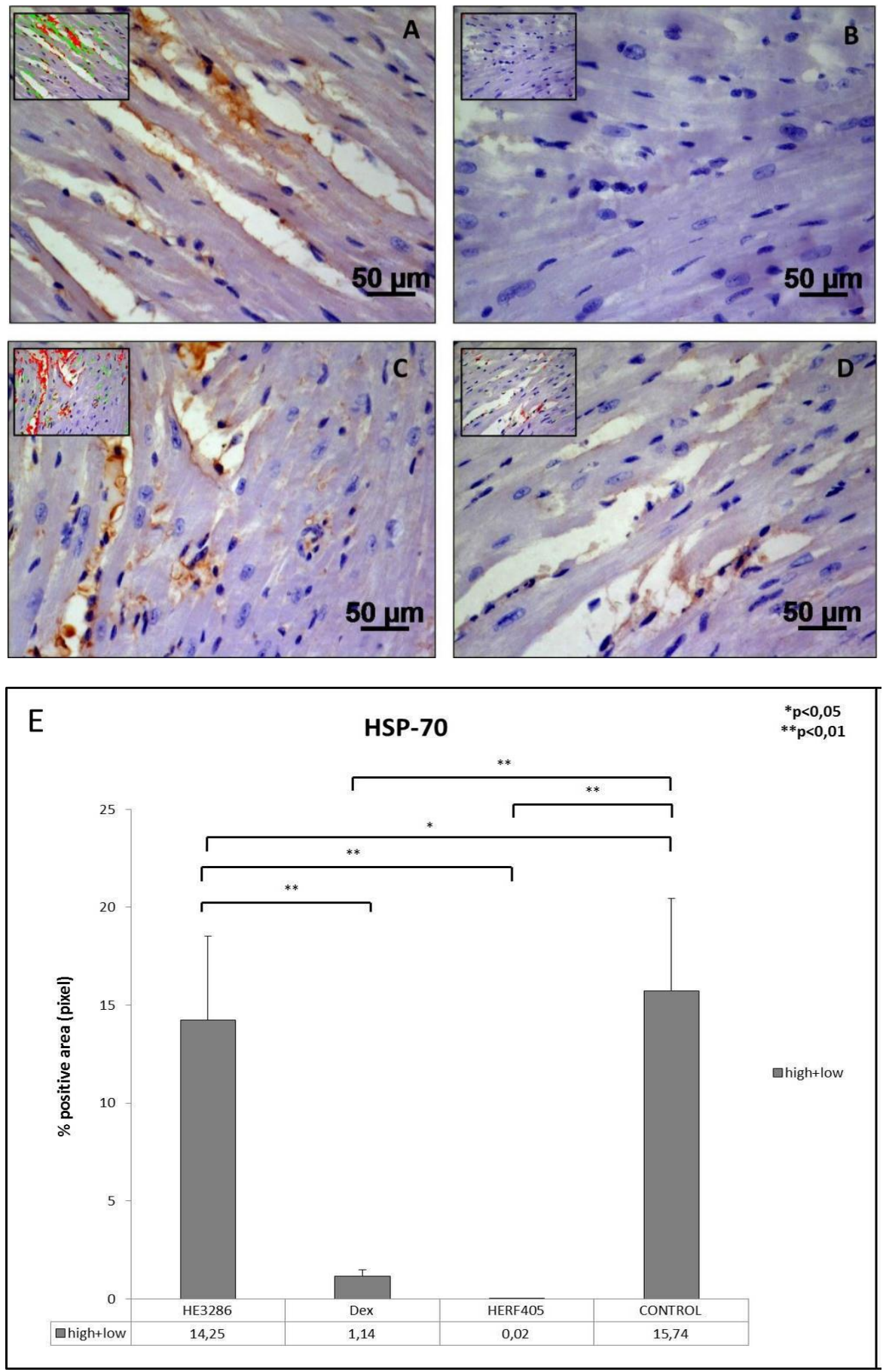

Figure 6. Cont. 


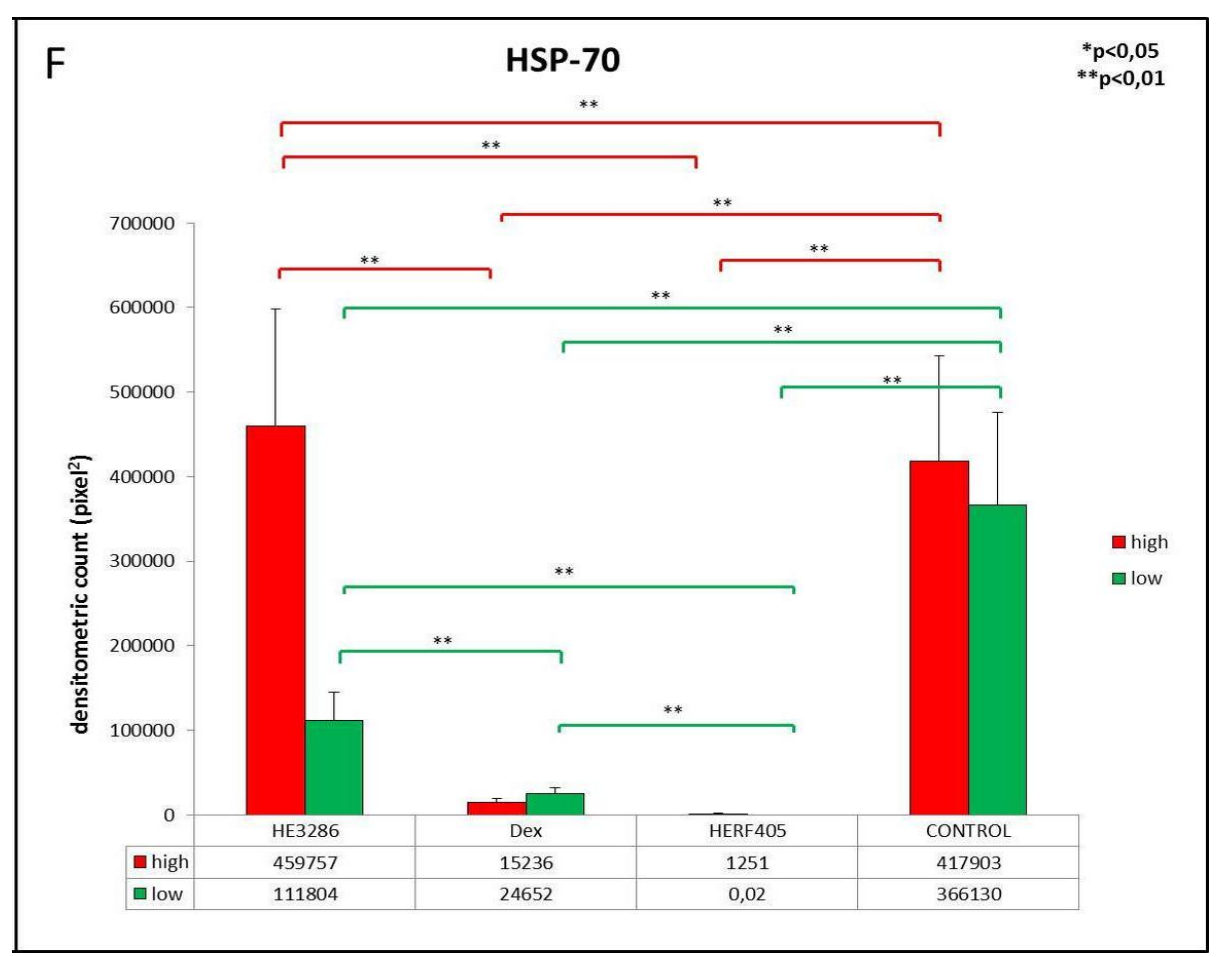

Figure 6. HSP-70 immunostaining in mice CB3V-induced myocarditis. A-insert in (A) section of heart tissue of control healthy mice with an evident HSP-70 immunostaining; the relative image analysis by software in which a high mixed to a low HSP-70 immunostaining was detected (respectively red and green color); B-insert in (B) section of heart tissue of experimental mice treated with vehicle alone (HERF405 group) in which the HSP-70 immunostaining was not detected; the relative image analysis by software confirming the datum; C-insert in (C) section of heart tissue of experimental HE3286-treated mice in which HSP-70 immunostaining was evident though slightly lower than in control healthy mice; the relative image analysis by software in which a mainly high HSP-70 immunostaining was evident with also a low HSP-70 immunostaining (respectively red and green color); D-insert in (D) section of heart tissue of experimental Dex-treated mice in which HSP-70 immunolabeling was slightly detected; the relative image analysis by software in which a mix of high and low HSP-70 immunolabeling (respectively red and green color) was detected but to a much smaller extent compared to HE3286 group; (A-D) original magnification 40×; scale bar: $50 \mu \mathrm{m}$; (E) A bar chart representing a comparison of the percentage areas of HSP-70-positive areas in HE3286 ( $n$. 12), Dex (n. 12), HERF405 (n. 12)-treated mice vs. control healthy $(n$. 5) mice, expressed as percentage positive, dark brown pixels of the analyzed fields (total of high + low immunostaining); (F) A bar chart representing a comparison of the immunostaining intensity in HSP-70-positive areas in HE3286 (n. 12), Dex ( $n$. 12), HERF405 (n. 12)-treated mice vs. control healthy ( $n .5)$ mice, expressed by densitometric count (pixel ${ }^{2}$ ) of dark brown pixels of the analyzed fields. Red bars, high immunostaining; green bars, low immunostaining. Data are presented as mean \pm SD. ${ }^{*} p<0.05 ;{ }^{* *} p<0.01$.

\section{Discussion}

Myocarditis, particularly types with viral etiology, are difficult to diagnose. How much inflammatory response contributes to myocardial injury and whether tissue alteration could be avoided by a more rapid decline of inflammation is currently unknown [2]. As reported previously, mediators that may play a role in the pathogenesis of the CVB-induced myocarditis include proinflammatory cytokines such as TNF- $\alpha$ and IL-6 [15-18] and MMPs [19,20]. In addition, studies showed that in different cardiac-related pathologic conditions, cardiomyocytes were actively involved in cytokine biosynthesis [21,22]. 
In pathological conditions such as dilated cardiomyopathy, heart failure and reperfusion injury, the activity of MMPs increases, thus effecting the cell and cell-matrix reassortment, playing a role in the abnormal remodeling of the heart [23,31-34]. ADAMs are also important enzymes affecting the basic structure of heart tissue by controlling cell-cell and cell-matrix interaction. When activated in pathological conditions, such as cardiomyopathy, collagen outgrowth and decomposition are accelerated [23]. All ADAMs are expressed in inflammatory cells [35]. Among ADAMs, ADAM-10 is involved in physiological [36,37] and pathological processes [29,30,38,39], and it is able to modulate inflammatory responses through several patterns [30,40-43]. In particular, ADAM-10 expression increases in dilated heart tissue from patients with atrial fibrillation, with chronic dilated cardiomyopathy and in some experimental-induced cardiomyopathy [23,44,45]. Human body normally reacts to tissue stress activating adaptive cellular mechanisms, which tend to restore a state of tissue homeostasis. Among them, the increased production of HSPs is well known [24,25,46,47]. HSPs, normally present in cells, increase when damage occurs after subsequent periods of oxidative stress and provide a rapid tissue remodeling $[26,28]$. HSPs preserve cellular integrity through several mechanisms $[26,46,47]$, and their immunoregulatory functions are highlighted in the activation of innate and adaptive immune system [48-51]. In cardiovascular biology and diseases, HSPs exhibit different protective functions, including inhibition of pro-inflammatory cytokines [48,52,53]. Among HSPs, HSP-70, whose expression is highlighted in the myocardial tissue as consequences of functional or pathological causes $[28,46,47,54]$, has the ability to repair proteins $[24,55]$.

Scientific research seeks to obtain new anti-inflammatory treatments for viral myocarditis, characterized by a low incidence of adverse effects, typical of glucocorticoids. HE3286 is one of the new drugs studied for this purpose. It is characterized by an ethynyl group at the $17 \alpha$ position, making the molecule orally bioavailable and stable to metabolism [56,57]. HE3286 has already been object of experimental studies [7-14,57-59]. Our results confirm the anti-inflammatory activity for HE3286. Results of our study on mice with CB3V-induced myocarditis demonstrated immunohistochemically that, in vehicle-treated mice, TNF- $\alpha$ and IL-6 expression are extensive and with a high level of intensity, a consequence of the inflammatory response. On the contrary, in mice treated with HE3286, a great reduction in TNF- $\alpha$ expression is evident also when compared to mice treated with Dex. Our results clearly indicate that HE3286 contributes to suppress the expression of TNF- $\alpha$ in CB3V-induced myocarditis, and in a better manner compared to Dex. Also, IL-6 expression is reduced in HE3286-treated mice, but the reduction is similar to that of mice treated with Dex, even if in the latter a high intensity of expression is also detected. Our results indicate that HE3286 has some efficacy in contributing to suppress expression of IL-6 in CB3V-induced myocarditis, as well as Dex. These results together support that HE3286, even while maintaining the necessary immune response, prevents an excessive inflammatory activity which may itself worsen the clinical picture of viral myocarditis. Furthermore, the activity of HE3286 seems to be more desirable than that of Dex, which is less incisive than HE286. On the other hand, our data show that MMP9 expression is evident, extensive and at comparative levels of intensity in all experimentally treated groups. This indicates that neither HE3286 nor Dex have some influence in mice CB3V-induced myocarditis, with respect to this enzyme. Results concerning ADAM10 highlighted that its expression in mice treated with HE3286 is similar to that of Dex-treated mice, and lower than that of experimental mice treated with vehicle alone. Our results indicate that HE3286 and Dex contribute in a similar manner to maintain slightly lower expression levels of ADAM10 in CB3V-induced myocarditis. Given the ability of HSP-70 to activate the adaptive cellular mechanisms, which tend to restore tissue homeostasis when an injury occurs, we evaluated its expression upon HE3286 administration. Results show that HSP-70 expression in mice treated with HE3286 is similar to that of healthy control mice, though slightly lower but with a mainly high intensity, and much higher than that of mice treated with Dex. Instead, in mice treated with vehicle alone, HSP-70 is not expressed, thereby suggesting that CB3V infection inhibits the remodeling function of HSP-70 in heart tissue. This indicates that HE3286 contributes to a better response of myocardial tissue to the cytological stress caused by a CB3V infection, as compared to other drugs such as Dex. From our 
immunohistochemical findings, HE3286 seems to have a significant role in reducing the inflammatory response that could lead to chronicity of myocarditis induced by CB3V, in a more efficient manner than Dex. In relation to the influence on cytokines involved in molecular mechanisms of cardiomyopathies, including tissue remodeling, at least those we have considered in our study (MMP-9, ADAM10 and HSP70), the action of HE3286 does not seem to be uniform. Histological analysis strengthens the immunohistochemical results, showing morphological improvement of heart tissue in mice treated with HE3286, better than in mice treated with Dex, thus demonstrating that HE3286 exerts beneficial effects on resolving the disease without apparent immunosuppressive activity. The mechanism by which HE3286 mediates its anti-inflammatory activity is not yet well known. A possible pathway includes ligand inactivation, modulation of ion channels, interaction with atypical receptors, and modulation of steroidogenic enzymes [57,60,61]. Previous studies associated the activity of HE3286 with increased regulatory $\mathrm{T}$ cells, maintaining immune homeostasis and preventing autoimmune disease $[57,62,63]$. Moreover HE3286 plays a role in the reduction of pro-inflammatory cytokines such as IL-17 and IL-6, involved in the biology of regulatory T cells $[12,57,64]$ and in the transition from acute to chronic inflammation $[57,61,65]$. From theliterature, HE3286 could downregulate NFkB-mediated pro-inflammatory cytokine production $[12,59,66-68]$ or decrease phosphorylation of IKK, NFKB, P38, and JNK associated with inhibition of TNF- $\alpha$ action $[59,69]$. Previous studies show that CVB3 infection induces ERK1/2 phosphorylation and that the inhibition of ERK1/2 activation attenuates viral replication and subsequent cell death [70-72]. It is proposed that ERK1/2 phosphorylation is triggered by viral protease-mediated cleavage of RasGAP during CVB3 infection [71]. In addition, it was reported that ERK1/2 regulates the entry of CVB3 into the host cells [73]. It is therefore likely that the protective action of HE3286 in the present model of CVB3-induced myocarditis may be due to its ability to inhibit the ERK1/2 pathway $[59,69]$.

Although the mechanism of action is not yet defined, HE3286 seems to have good pharmaceutical properties, including good oral bioavailability and resistance to metabolism $[56,57]$. Thus its use in disease settings of chronic inflammation, in which administration over a long period is more opportune, seems to be more adequate than glucocorticoids [57].

\section{Conclusions}

Since timely diagnosis is crucial for resolution of myocarditis but often difficult due to the oligosymptomatic presentation of the disease in the early phases, we remark that a support therapy can help to improve the evolution of myocarditis. We believe that this study could have a clinical relevance, encouraging the scientific community to find treatments, besides the existing ones, that could have some beneficial effects with respect to the progression of viral myocarditis and hence its possible chronicization. HE3286 is one of the new drugs studied for this purpose, and our results provide indications for further investigations. A limitation of the present study is the lack of other quantification methods such as Western blot, in order to confirm and support the results obtained from paraffin-embedded samples.

Acknowledgments: The authors thank Iain Halliday for making corrections to the paper and Pietro Asero for technical assistance. This study was supported by grants-in-aid from FIR 2014-2016, (cod. 314509), University of Catania, Italy. The funder had no role in the design of the study, collection and analysis of the data, decision to publish, or the preparation of the manuscript.

Author Contributions: All authors have made substantial intellectual contributions to the conception and design of the study as well as data acquisition, analysis and interpretation. Marta Anna Szychlinska, Salvatore Giunta, Soraya Scuderi, Roberta Passanisi, Federica Fidone and Paolo Fagone carried out the experimental in vivo work. Rosa Imbesi and Carla Loreto carried out the study execution, analyses and literature research. Ferdinando Nicoletti and Sergio Castorina carried out the study execution, contributed to data collection and provided technical assistance. Francesca Maria Trovato supervised planning and editing the manuscript writing and correspondence. Paola Castrogiovanni conceived the study design, write the paper, coordinated the execution of experimental procedures, the analysis and the discussion of results. All authors contributed to data interpretation and manuscript preparation. All authors approved the final submitted version.

Conflicts of Interest: The authors declare no conflict of interest. 


\section{References}

1. Gouda, Z.A.; Elewa, Y.H.A.; Selim, A.O. Histological architecture of cardiac myofibers composing the left ventricle of murine heart. J. Histol. Histopathol. 2015, 2. [CrossRef]

2. Kühl, U.; Schultheiss, H.-P.P. Viral myocarditis. Swiss Med. Wkly. 2014, 144. [CrossRef] [PubMed]

3. Schultz, J.C.; Hilliard, A.A.; Cooper, L.T.; Rihal, C.S. Diagnosis and treatment of viral myocarditis. Mayo Clin. Proc. 2009, 84, 1001-1009. [CrossRef]

4. Nakamura, H.; Kunitsugu, I.; Fukuda, K.; Matsuzaki, M.; Sano, M. Diverse stage-dependent effects of glucocorticoids in a murine model of viral myocarditis. J. Cardiol. 2013, 61, 237-242. [CrossRef] [PubMed]

5. Aziz, K.U.; Patel, N.; Sadullah, T.; Tasneem, H.; Thawerani, H.; Talpur, S. Acute viral myocarditis: Role of immunosuppression: A prospective randomised study. Cardiol. Young 2010, 20, 509-515. [CrossRef] [PubMed]

6. Moreels, M.; Delforge, M.-L.L.; Renard, M. Fulminant myocarditis with dramatic response to corticoids. Acta Cardiol. 2010, 65, 97-99. [CrossRef] [PubMed]

7. Khan, R.S.; Dine, K.; Luna, E.; Ahlem, C.; Shindler, K.S. HE3286 reduces axonal loss and preserves retinal ganglion cell function in experimental optic neuritis. Investig. Ophthalmol. Vis. Sci. 2014, 55, 5744-5751. [CrossRef] [PubMed]

8. Auci, D.; Kaler, L.; Subramanian, S.; Huang, Y.; Frincke, J.; Reading, C.; Offner, H. A new orally bioavailable synthetic androstene inhibits collagen-induced arthritis in the mouse: Androstene hormones as regulators of regulatory T cells. Ann. N. Y. Acad. Sci. 2007, 1110, 630-640. [CrossRef] [PubMed]

9. Auci, D.L.; Reading, C.L.; Frincke, J.M. 7-hydroxy androstene steroids and a novel synthetic analogue with reduced side effects as a potential agent to treat autoimmune diseases. Autoimmunity Rev. 2009, 8, 369-372. [CrossRef] [PubMed]

10. Hegen, M.; Keith, J.C.; Collins, M.; Nickerson-Nutter, C.L. Utility of animal models for identification of potential therapeutics for rheumatoid arthritis. Ann. Rheumatic Dis. 2008, 67, 1505-1515. [CrossRef] [PubMed]

11. Nicoletti, F.; Philippens, I.; Fagone, P.; Ahlem, C.N.; Reading, C.L.; Frincke, J.M.; Auci, D.L. $17 \alpha$-ethynyl-androst-5-ene-3 $\beta, 7 \beta, 17 \beta$-triol (HE3286) is neuroprotective and reduces motor impairment and neuroinflammation in a murine mptp model of parkinson's disease. Parkinson's Dis. 2012, 2012. [CrossRef] [PubMed]

12. Offner, H.; Firestein, G.S.; Boyle, D.L.; Pieters, R.; Frincke, J.M.; Garsd, A.; White, S.K.; Reading, C.L.; Auci, D.L. An orally bioavailable synthetic analog of an active dehydroepiandrosterone metabolite reduces established disease in rodent models of rheumatoid arthritis. J. Pharmacol. Exp. Ther. 2009, 329, 1100-1109. [CrossRef] [PubMed]

13. Reading, C.L.; Flores-Riveros, J.; Stickney, D.R.; Frincke, J.M. An anti-inflammatory sterol decreases obesity-related inflammation-induced insulin resistance and metabolic dysregulation. Med. Inflamm. 2013, 2013. [CrossRef] [PubMed]

14. Reading, C.L.; Stickney, D.R.; Flores-Riveros, J.; Destiche, D.A.; Ahlem, C.N.; Cefalu, W.T.; Frincke, J.M. A synthetic anti-inflammatory sterol improves insulin sensitivity in insulin-resistant obese impaired glucose tolerance subjects. Obesity 2013, 21. [CrossRef] [PubMed]

15. Corsten, M.F.; Schroen, B.; Heymans, S. Inflammation in viral myocarditis: Friend or foe? Trends Mol. Med. 2012, 18, 426-437. [CrossRef] [PubMed]

16. Fairweather, D.; Frisancho-Kiss, S.; Gatewood, S.; Njoku, D.; Steele, R.; Barrett, M.; Rose, N.R. Mast cells and innate cytokines are associated with susceptibility to autoimmune heart disease following coxsackievirus B3 infection. Autoimmunity 2004, 37, 131-145. [CrossRef] [PubMed]

17. Lane, J.R.; Neumann, D.A.; Lafond-Walker, A.; Herskowitz, A.; Rose, N.R. Role of IL-1 and tumor necrosis factor in coxsackie virus-induced autoimmune myocarditis. J. Immunol. 1993, 151, 1682-1690. [PubMed]

18. Rose, N.R. Critical cytokine pathways to cardiac inflammation. J. Interferon Cytokine Res. Off. J. Int. Soc. Interferon Cytokine Res. 2011, 31, 705-710. [CrossRef] [PubMed]

19. Rehren, F.; Ritter, B.; Dittrich-Breiholz, O.; Henke, A.; Lam, E.; Kati, S.; Kracht, M.; Heim, A. Induction of a broad spectrum of inflammation-related genes by coxsackievirus B3 requires interleukin-1 signaling. Med. Microbiol. Immunol. 2013, 202, 11-23. [CrossRef] [PubMed] 
20. Rutschow, S.; Leschka, S.; Westermann, D.; Puhl, K.; Weitz, A.; Ladyszenskij, L.; Jaeger, S.; Zeichhardt, H.; Noutsias, M.; Schultheiss, H.-P.P.; et al. Left ventricular enlargement in coxsackievirus-B3 induced chronic myocarditis-Ongoing inflammation and an imbalance of the matrix degrading system. Eur. J. Pharmacol. 2010, 630, 145-151. [CrossRef] [PubMed]

21. Jibiki, T.; Terai, M.; Tateno, S.; Toyozaki, T.; Horie, H.; Nakajima, H.; Niwa, K.; Niimi, H. Expression of tumor necrosis factor- $\alpha$ protein in the myocardium in fatal myocarditis. Pediatr. Int. Off. J. Jpn. Pediatr. Soc. 2000, 42, 43-47. [CrossRef]

22. Torre-Amione, G.; Kapadia, S.; Lee, J.; Durand, J.B.; Bies, R.D.; Young, J.B.; Mann, D.L. Tumor necrosis factor- $\alpha$ and tumor necrosis factor receptors in the failing human heart. Circulation 1996, 93, 704-711. [CrossRef] [PubMed]

23. Lim, S.C. Interrelation between expression of ADAM 10 and MMP 9 and synthesis of peroxynitrite in doxorubicin induced cardiomyopathy. Biomol. Ther. 2013, 21, 371-380. [CrossRef] [PubMed]

24. Castrogiovanni, P.; Imbesi, R. Oxidative stress and skeletal muscle in exercise. Ital. J. Anat. Embryol. 2012, 117, 107-117. [PubMed]

25. Musumeci, G.; Castrogiovanni, P.; Trovato, F.M.; Parenti, R.; Szychlinska, M.A.; Imbesi, R. Pregnancy, embryo-fetal development and nutrition: Physiology around fetal programming. J. Histol. Histopathol. 2015, 2. [CrossRef]

26. Musumeci, G.; Maria Trovato, F.; Imbesi, R.; Castrogiovanni, P. Effects of dietary extra-virgin olive oil on oxidative stress resulting from exhaustive exercise in rat skeletal muscle: A morphological study. Acta Histochem. 2014, 116, 61-69. [CrossRef] [PubMed]

27. Papageorgiou, A.-P.P.; Heymans, S. Interactions between the extracellular matrix and inflammation during viral myocarditis. Immunobiology 2012, 217, 503-510. [CrossRef] [PubMed]

28. Senf, S.M.; Howard, T.M.; Ahn, B.; Ferreira, L.F.; Judge, A.R. Loss of the inducible Hsp70 delays the inflammatory response to skeletal muscle injury and severely impairs muscle regeneration. PLoS ONE 2013, 8, e62687.

29. Musumeci, G.; Coleman, R.; Imbesi, R.; Magro, G.; Parenti, R.; Szychlinska, M.A.; Scuderi, R.; Cinà, C.S.; Castorina, S.; Castrogiovanni, P. ADAM-10 could mediate cleavage of n-cadherin promoting apoptosis in human atherosclerotic lesions leading to vulnerable plaque: A morphological and immunohistochemical study. Acta Histochem. 2014, 116, 1148-1158. [CrossRef] [PubMed]

30. Musumeci, G.; Loreto, C.; Imbesi, R.; Szychlinska, M.A.; Castrogiovanni, P. N-cadherin, ADAM-10 and aquaporin1 expression in lung tissue exposed to fluoro-edenite fibres: An immunohistochemical study. J. Histol. Histopathol. 2015, 30, 987-999.

31. Cheung, P.Y.; Sawicki, G.; Wozniak, M.; Wang, W.; Radomski, M.W.; Schulz, R. Matrix metalloproteinase-2 contributes to ischemia-reperfusion injury in the heart. Circulation 2000, 101, 1833-1839. [CrossRef] [PubMed]

32. Mann, D.L.; Spinale, F.G. Activation of matrix metalloproteinases in the failing human heart: Breaking the tie that binds. Circulation 1998, 98, 1699-1702. [CrossRef] [PubMed]

33. Spinale, F.G. Matrix metalloproteinases: Regulation and dysregulation in the failing heart. Circ. Res. 2002, 90, 520-530. [CrossRef] [PubMed]

34. Thomas, C.V.; Coker, M.L.; Zellner, J.L.; Handy, J.R.; Crumbley, A.J.; Spinale, F.G. Increased matrix metalloproteinase activity and selective upregulation in LV myocardium from patients with end-stage dilated cardiomyopathy. Circulation 1998, 97, 1708-1715. [CrossRef] [PubMed]

35. Dijkstra, A.; Postma, D.S.; Noordhoek, J.A.; Lodewijk, M.E.; Kauffman, H.F.; ten Hacken, N.H.; Timens, W. Expression of ADAMs ("a disintegrin and metalloprotease") in the human lung. Virch. Arch. Int. J. Pathol. 2009, 454, 441-449. [CrossRef] [PubMed]

36. Reiss, K.; Saftig, P. The "a disintegrin and metalloprotease" (ADAM) family of sheddases: Physiological and cellular functions. Semin. Cell Dev. Biol. 2009, 20, 126-137. [CrossRef] [PubMed]

37. Tousseyn, T.; Jorissen, E.; Reiss, K.; Hartmann, D. (Make) stick and cut loose-Disintegrin metalloproteases in development and disease. Birth Defects Res. Part C Embryo Today Rev. 2006, 78, 24-46. [CrossRef] [PubMed]

38. Kohutek, Z.A.; di Pierro, C.G.; Redpath, G.T.; Hussaini, I.M. ADAM-10-mediated n-cadherin cleavage is protein kinase C- $\alpha$ dependent and promotes glioblastoma cell migration. J. Neurosci. Off. J. Soc. Neurosci. 2009, 29, 4605-4615. [CrossRef] [PubMed] 
39. Musumeci, G.; Imbesi, R.; Magro, G.; Parenti, R.; Szychlinska, M.A.; Scuderi, R.; Castorina, S.; Castrogiovanni, P. $\mathrm{N}$-cadherin has a protective role in stable human atherosclerotic plaques: A morphological and immunohistochemical study. J. Histol. Histopathol. 2014, 1. [CrossRef]

40. Hikita, A.; Tanaka, N.; Yamane, S.; Ikeda, Y.; Furukawa, H.; Tohma, S.; Suzuki, R.; Tanaka, S.; Mitomi, H.; Fukui, N. Involvement of a disintegrin and metalloproteinase 10 and 17 in shedding of tumor necrosis factor- $\alpha$. Biochem. Cell Biol. 2009, 87, 581-593. [CrossRef] [PubMed]

41. Hundhausen, C.; Schulte, A.; Schulz, B.; Andrzejewski, M.G.; Schwarz, N.; von Hundelshausen, P.; Winter, U.; Paliga, K.; Reiss, K.; Saftig, P.; et al. Regulated shedding of transmembrane chemokines by the disintegrin and metalloproteinase 10 facilitates detachment of adherent leukocytes. J. Immunol. 2007, 178, 8064-8072. [CrossRef] [PubMed]

42. Schulte, M.; Reiss, K.; Lettau, M.; Maretzky, T.; Ludwig, A.; Hartmann, D.; de Strooper, B.; Janssen, O.; Saftig, P. ADAM10 regulates fasl cell surface expression and modulates fasl-induced cytotoxicity and activation-induced cell death. Cell Death Differ. 2007, 14, 1040-1049. [CrossRef] [PubMed]

43. Schulz, B.; Pruessmeyer, J.; Maretzky, T.; Ludwig, A.; Blobel, C.P.; Saftig, P.; Reiss, K. ADAM10 regulates endothelial permeability and T-cell transmigration by proteolysis of vascular endothelial cadherin. Circ. Res. 2008, 102, 1192-1201. [CrossRef] [PubMed]

44. Arndt, M.; Lendeckel, U.; Röcken, C.; Nepple, K.; Wolke, C.; Spiess, A.; Huth, C.; Ansorge, S.; Klein, H.U.; Goette, A. Altered expression of ADAMs (a disintegrin and metalloproteinase) in fibrillating human atria. Circulation 2002, 105, 720-725. [CrossRef] [PubMed]

45. Hunt, M.J.; Aru, G.M.; Hayden, M.R.; Moore, C.K.; Hoit, B.D.; Tyagi, S.C. Induction of oxidative stress and disintegrin metalloproteinase in human heart end-stage failure. Am. J. Physiol. Lung Cell. Mol. Physiol. 2002, 283. [CrossRef] [PubMed]

46. Kayani, A.C.; Close, G.L.; Dillmann, W.H.; Mestril, R.; Jackson, M.J.; McArdle, A. Overexpression of HSP10 in skeletal muscle of transgenic mice prevents the age-related fall in maximum tetanic force generation and muscle cross-sectional area. Am. J. Physiol. Regul. Integr. Comp. Physiol. 2010, 299. [CrossRef] [PubMed]

47. Staib, J.L.; Tümer, N.; Powers, S.K. Increased temperature and protein oxidation lead to HSP72 mRNA and protein accumulation in the in vivo exercised rat heart. Exp. Physiol. 2009, 94, 71-80. [CrossRef] [PubMed]

48. Gulbahar, M.Y.; Kabak, Y.B.; Karayigit, M.O.; Yarim, M.; Guvenc, T.; Parlak, U. The expressions of HSP70 and $\alpha \mathrm{b}$-crystallin in myocarditis associated with foot-and-mouth disease virus in lambs. J. Vet. Sci. 2011, 12, 65-73. [CrossRef] [PubMed]

49. Radons, J.; Multhoff, G. Immunostimulatory functions of membrane-bound and exported heat shock protein 70. Exerc. Immunol. Rev. 2005, 11, 17-33. [PubMed]

50. Tsan, M.-F.F.; Gao, B. Heat shock protein and innate immunity. Cell. Mol. Immunol. 2004, 1, $274-279$. [PubMed]

51. Tsan, M.-F.F.; Gao, B. Cytokine function of heat shock proteins. Am. J. Physiol. Cell Physiol. $2004,286$. [CrossRef] [PubMed]

52. Delogu, G.; Signore, M.; Mechelli, A.; Famularo, G. Heat shock proteins and their role in heart injury. Curr. Opin. Crit. Care 2002, 8, 411-416. [CrossRef] [PubMed]

53. Kirchhoff, S.R.; Gupta, S.; Knowlton, A.A. Cytosolic heat shock protein 60, apoptosis, and myocardial injury. Circulation 2002, 105, 2899-2904. [CrossRef] [PubMed]

54. Jain, K.; Suryakumar, G.; Prasad, R.; Ganju, L. Upregulation of cytoprotective defense mechanisms and hypoxia-responsive proteins imparts tolerance to acute hypobaric hypoxia. High Alt. Med. Biol. 2013, 14, 65-77. [CrossRef] [PubMed]

55. McArdle, A.; Vasilaki, A.; Jackson, M. Exercise and skeletal muscle ageing: Cellular and molecular mechanisms. Ageing Res. Rev. 2002, 1, 79-93. [CrossRef]

56. Ahlem, C.N.; Kennedy, M.R.; Page, T.M.; Reading, C.L.; White, S.K.; McKenzie, J.J.; Cole, P.I.; Stickney, D.R.; Frincke, J.M. Studies of the pharmacology of $17 \alpha$-ethynyl-androst-5-ene-3 $\beta, 7 \beta, 17 \beta$-triol, a synthetic anti-inflammatory androstene. Int. J. Clin. Exp. Med. 2011, 4, 119-135. [PubMed]

57. Auci, D.L.; Mangano, K.; Destiche, D.; White, S.K.; Huang, Y.; Boyle, D.; Frincke, J.; Reading, C.L.; Nicoletti, F. Oral treatment with HE3286 ameliorates disease in rodent models of rheumatoid arthritis. Int. J. Mol. Med. 2010, 25, 625-633. [PubMed] 
58. Ahlem, C.; Auci, D.; Mangano, K.; Reading, C.; Frincke, J.; Stickney, D.; Nicoletti, F. HE3286: A novel synthetic steroid as an oral treatment for autoimmune disease. Ann. N. Y. Acad. Sci. 2009, 1173, 781-790. [CrossRef] [PubMed]

59. Conrad, D.; Wang, A.; Pieters, R.; Nicoletti, F.; Mangano, K.; van Heeckeren, A.M.; White, S.K.; Frincke, J.M.; Reading, C.L.; Stickney, D.; et al. HE3286, an oral synthetic steroid, treats lung inflammation in mice without immune suppression. J. Inflamm. 2010, 7. [CrossRef] [PubMed]

60. Lathe, R. Steroid and sterol 7-hydroxylation: Ancient pathways. Steroids 2002, 67,967-977. [CrossRef]

61. Wang, T.; Villegas, S.; Huang, Y.; White, S.K.; Ahlem, C.; Lu, M.; Olefsky, J.M.; Reading, C.; Frincke, J.M.; Alleva, D; et al. Amelioration of glucose intolerance by the synthetic androstene HE3286: Link to inflammatory pathways. J. Pharmacol. Exp. Ther. 2010, 333, 70-80. [CrossRef] [PubMed]

62. Kosiewicz, M.M.; Auci, D.L.; Fagone, P.; Mangano, K.; Caponnetto, S.; Tucker, C.F.; Azeem, N.; White, S.K.; Frincke, J.M.; Reading, C.L.; et al. HE3286, an orally bioavailable synthetic analogue of an active DHEA metabolite suppresses spontaneous autoimmune diabetes in the non-obese diabetic (nod) mouse. Eur. J. Pharmacol. 2011, 658, 257-262. [CrossRef] [PubMed]

63. Zwar, T.D.; van Driel, I.R.; Gleeson, P.A. Guarding the immune system: Suppression of autoimmunity by CD4+CD25+ immunoregulatory T cells. Immunol. Cell Biol. 2006, 84, 487-501. [CrossRef] [PubMed]

64. Lohr, J.; Knoechel, B.; Wang, J.J.; Villarino, A.V.; Abbas, A.K. Role of IL-17 and regulatory T lymphocytes in a systemic autoimmune disease. J. Exp. Med. 2006, 203, 2785-2791. [CrossRef] [PubMed]

65. Marin, V.; Montero-Julian, F.A.; Grès, S.; Boulay, V.; Bongrand, P.; Farnarier, C.; Kaplanski, G. The IL-6-soluble IL-6 $\alpha$ autocrine loop of endothelial activation as an intermediate between acute and chronic inflammation: An experimental model involving thrombin. J. Immunol. 2001, 167, 3435-3442. [CrossRef] [PubMed]

66. Fujita, M.; Nakanishi, Y. The pathogenesis of copd: Lessons learned from in vivo animal models. Med. Sci. Monit. Int. Med. J. Exp. Clin. Res. 2007, 13, RA19-RA24.

67. Koehler, D.R.; Downey, G.P.; Sweezey, N.B.; Tanswell, A.K.; Hu, J. Lung inflammation as a therapeutic target in cystic fibrosis. Am. J. Respir. Cell Mol. Biol. 2004, 31, 377-381. [CrossRef] [PubMed]

68. Lee, H.S.; Moon, C.; Lee, H.W.; Park, E.-M.M.; Cho, M.-S.S.; Kang, J.L. Src tyrosine kinases mediate activations of NF-кB and integrin signal during lipopolysaccharide-induced acute lung injury. J. Immunol. 2007, 179, 7001-7011. [CrossRef] [PubMed]

69. Lu, M.; Patsouris, D.; Li, P.; Flores-Riveros, J.; Frincke, J.M.; Watkins, S.; Schenk, S.; Olefsky, J.M. A new antidiabetic compound attenuates inflammation and insulin resistance in zucker diabetic fatty rats. Am. J. Physiol. Endocrinol. Metabol. 2010, 298. [CrossRef] [PubMed]

70. Cunningham, K.A.; Chapman, N.M.; Carson, S.D. Caspase-3 activation and ERK phosphorylation during CVB3 infection of cells: Influence of the coxsackievirus and adenovirus receptor and engineered variants. Virus Res. 2003, 92, 179-186. [CrossRef]

71. Huber, M.; Watson, K.A.; Selinka, H.C.; Carthy, C.M.; Klingel, K.; McManus, B.M.; Kandolf, R. Cleavage of rasgap and phosphorylation of mitogen-activated protein kinase in the course of coxsackievirus B3 replication. J. Virol. 1999, 73, 3587-3594. [PubMed]

72. Luo, H.; Yanagawa, B.; Zhang, J.; Luo, Z.; Zhang, M.; Esfandiarei, M.; Carthy, C.; Wilson, J.E.; Yang, D.; McManus, B.M. Coxsackievirus B3 replication is reduced by inhibition of the extracellular signal-regulated kinase (ERK) signaling pathway. J. Virol. 2002, 76, 3365-3373. [CrossRef] [PubMed]

73. Marchant, D.; Sall, A.; Si, X.; Abraham, T.; Wu, W.; Luo, Z.; Petersen, T.; Hegele, R.G.; McManus, B.M. ERK map kinase-activated ARF6 trafficking directs coxsackievirus type B3 into an unproductive compartment during virus host-cell entry. J. Gen. Virol. 2009, 90, 854-862. [CrossRef] [PubMed]

(C) 2016 by the authors; licensee MDPI, Basel, Switzerland. This article is an open access article distributed under the terms and conditions of the Creative Commons by Attribution (CC-BY) license (http://creativecommons.org/licenses/by/4.0/). 